\title{
Repeated electromagnetic induction measurements for mapping soil moisture at the field scale: validation with data from a wireless soil moisture monitoring network
}

\author{
Edoardo Martini $^{1}$, Ulrike Werban ${ }^{1}$, Steffen Zacharias ${ }^{1}$, Marco Pohle ${ }^{1}$, Peter Dietrich ${ }^{1,2}$, and Ute Wollschläger ${ }^{3}$ \\ ${ }^{1}$ Dept. Monitoring and Exploration Technologies, UFZ - Helmholtz Centre for Environmental Research, Permoserstraße 15, \\ 04318 Leipzig, Germany \\ ${ }^{2}$ Centre for Applied Geoscience, University of Tübingen, Hölderlinstraße 12, 72074 Tübingen, Germany \\ ${ }^{3}$ Dept. Soil Physics, UFZ - Helmholtz Centre for Environmental Research, Theodor-Lieser-Straße 4, \\ 06120 Halle (Saale), Germany
}

Correspondence to: Edoardo Martini (edoardo.martini@ufz.de)

Received: 25 February 2016 - Published in Hydrol. Earth Syst. Sci. Discuss.: 4 March 2016

Revised: 6 January 2017 - Accepted: 9 January 2017 - Published: 26 January 2017

\begin{abstract}
Electromagnetic induction (EMI) measurements are widely used for soil mapping, as they allow fast and relatively low-cost surveys of soil apparent electrical conductivity (ECa). Although the use of non-invasive EMI for imaging spatial soil properties is very attractive, the dependence of ECa on several factors challenges any interpretation with respect to individual soil properties or states such as soil moisture $(\theta)$. The major aim of this study was to further investigate the potential of repeated EMI measurements to map $\theta$, with particular focus on the temporal variability of the spatial patterns of ECa and $\theta$. To this end, we compared repeated EMI measurements with high-resolution $\theta$ data from a wireless soil moisture and soil temperature monitoring network for an extensively managed hillslope area for which soil properties and $\theta$ dynamics are known. For the investigated site, (i) ECa showed small temporal variations whereas $\theta$ varied from very dry to almost saturation, (ii) temporal changes of the spatial pattern of ECa differed from those of the spatial pattern of $\theta$, and (iii) the ECa- $\theta$ relationship varied with time. Results suggest that (i) depending upon site characteristics, stable soil properties can be the major control of ECa measured with EMI, and (ii) for soils with low clay content, the influence of $\theta$ on ECa may be confounded by changes of the electrical conductivity of the soil solution. Further, this study discusses the complex interplay between factors controlling ECa and $\theta$, and the use of EMI-based ECa data with respect to hydrological applications.
\end{abstract}

\section{Introduction}

Electromagnetic induction (EMI) methods are widely used for soil mapping, as they allow fast and relatively low-cost surveys of soil apparent electrical conductivity (ECa) over areas up to several squared kilometers in size (McNeil, 1980). The main strength of the EMI method is that the induction principle does not require direct contact with the ground. Consequently, a survey carried out using EMI sensors can be accomplished faster than an equivalent survey carried out with other instruments. Normally, surveys can be performed by a single operator, and a GPS receiver connected to the instrument allows for collection of georeferenced ECa data. Measurements of ECa using EMI have been in use since the 1970's, initially having been used for applications related to soil salinity. Since then, various environmental questions have been addressed using the EMI method, as discussed in the recent review of Doolittle and Brevik (2014). Although the use of non-invasive geophysical techniques for soil mapping is very attractive, the dependence of the measured ECa on a number of parameters complicates any interpretation to determine soil properties or states (Robinson et al., 2012). A firm understanding of the spatial and temporal variability of soil electrical conductivity (EC) and an appreciation for its highly complex interactions with static soil properties and dynamic state variables, particularly at low-salt concentrations, is needed (Sudduth et al., 2001, 2005; McCutcheon et al., 2006), and it is helpful for understanding when EMI 
can be applied, as it is not applicable under all circumstances (Robinson et al., 2012).

The theory and basic principle of EMI are based on the soil equivalent resistance model (Sauer et al., 1955). Soil EC is assumed to arise from three conductance pathways through the soil: (i) a conductance pathway traveling through a continuous soil solution, (ii) a conductance pathway traveling through the solid particles, and (iii) an alternating solidliquid pathway (Rhoades et al., 1989). In this formulation, the total soil water content is separated into the fraction of water content in the fine pores (mostly adsorbed by the clay minerals, contributing to the alternating solid-liquid pathway) and the water content in the large pores (which contributes to the continuous liquid pathway). The soil EC is influenced by the volumetric water content $(\theta)$, the EC of the fractions of soil solution $\left(\mathrm{EC}_{\mathrm{w}}\right)$, as well as by the volume of the solid particles and their $\mathrm{EC}\left(\mathrm{EC}_{\mathrm{s}}\right)$. As a consequence, several factors influence EC (Friedman, 2005). A higher clay content and/or higher organic matter content usually correspond to a higher content of adsorbed water (i.e., higher $\theta$ ), higher $\mathrm{EC}_{\mathrm{s}}$, and higher cation exchange capacity (CEC), thus potentially leading to higher EC (e.g., Hudson, 1994; Dingman, 2002; Lal and Shukla, 2004; Roth, 2012). Moreover, of particular importance is $\mathrm{EC}_{\mathrm{w}}$, which often increases with higher CEC: as soil water interacts with the soil minerals (especially clay) and with soil organic matter (SOM), ions from the soil minerals can be released into the soil solution and, conversely, free ions can be adsorbed to equilibrate the mineral surface charges. In this respect, the initial EC of rain water and its residence time in the soil may play a key role along with the mineralogical composition of the soil. Soil compaction affects EC due to the reduced porosity and increased soil particle-to-particle contact (Corwin et al., 2008; Brevik and Fenton, 2004). Soil temperature also affects EC, which increases approximately $1.9 \%$ per degree centigrade (U.S.D.A., 1954; Corwin and Lesch, 2005). All these mechanisms contribute to the complexity of EC and soil property relationships. Corwin et al. (2008) and Farahani et al. (2005) highlighted that the EC versus soil property functions are expected to be temporally variable unless $\mathrm{EC}_{\mathrm{w}}$ and $\theta$ remain relatively unchanged, assuming $\mathrm{EC}_{\mathrm{S}}$ to be stable at the temporal scale of observation.

The parameter measured by EMI sensors refers to a certain volume of soil material according to a complex depthweighting, thus it is indicated as apparent electrical conductivity ECa. Callegary et al. (2007, 2012) discussed this concept using a forward model of electromagnetic field propagation, and found that the sensitivity of any EMI sensor, as well as the depth of investigation, can differ significantly from those suggested by McNeil (1980). Nevertheless, it appears clear that the final ECa reading of any EMI device is a complex physicochemical measurement which results from the propagation of the EM field within the volume of investigation and its interaction with stable and transient soil properties and/or states, and that the effective measurement depth and volume of investigation of an EMI sensor may vary at different times and locations (Sudduth et al., 2001; Corwin and Lesch, 2005; Farahani et al., 2005; Callegary et al., 2007; Corwin et al., 2008; Werban et al., 2009; Zhu et al., 2010; Robinson et al., 2012; Callegary et al., 2012).

The fact that ECa measured with EMI responds to variations of several soil properties encouraged its use for a broad range of scopes. Examples of the application of EMI-based ECa measurements include soil salinity (e.g., Doolittle et al., 2001; Heilig et al., 2011), spatial patterns of soil texture (e.g., Abdu et al., 2008; Heil and Schmidhalter, 2012), lateral boundaries between soil types (e.g., Anderson-Cook et al., 2002; James et al., 2003), depth of clay-rich layers (e.g., Saey et al., 2009; Doolittle at al., 1994), clay content (e.g., King et al., 2005; Weller et al., 2007), soil compaction (e.g., Al-Gaadi, 2012; Islam et al., 2014), soil CEC (e.g., Headley et al., 2004; Triantafilis et al., 2009), soil organic carbon (e.g., Martinez et al., 2009; Altdorff et al., 2016), assessment of soil quality (e.g., Johnson et al., 2001; Corwin and Lesch, 2005), detection of buried services (e.g., Won and Huang, 2004; El-Quady et al., 2014), and mapping of active layer thickness in permafrost areas (e.g., Hauck and Kneisel, 2008; Dafflon et al., 2013). ECa measurements are widely used in the context of precision agriculture for, e.g., refining existing soil maps (e.g., Doolittle et al., 2008; Martini et al., 2013), precision farming (e.g., Lück et al., 2009; Scudiero et al., 2015), and harvest zoning (e.g., Frogbrook and Oliver, 2007; Priori et al., 2013).

EMI has become widely used to determine soil water content or to study hydrological processes within the field of hydrogeophysics (Binley et al., 2015; Huang et al., 2016, 2017). In a recent work, Calamita et al. (2015) listed 20 of the papers which address the use of EMI sensors for the determination of spatial and temporal patterns of $\theta$. This summary provides a clear illustration of the differences among $\mathrm{ECa}-\theta$ studies: estimation of $\theta$ was attempted for different soils and under varying climatic conditions, from the plot to the small catchment scale, with different temporal resolutions, and with different measurement schemes. The temporal resolution varied between one measurement date up to several days or years. Soil water content was estimated with a variety of probes down to different depths of the soil profiles and sometimes total water storage down to a certain soil depth was inferred. However, discrepancies exist between the depth of soil moisture measurements and the theoretical investigation depth of the EMI sensor in use.

Because factors affecting ECa readings are complex and often interrelated, accurate interpretations have been a challenge (Zhu et al., 2010). In particular, the transient nature of soil water content and soil temperature was found to complicate the characterization of ECa variability by altering its response to a given soil property during a given mapping event (McCutcheon et al., 2006), such that the spatial and temporal variance of $\theta$ explained by EMI-ECa data is strongly unstable (Calamita et al., 2015). Repeated EMI measure- 
ments at one site (which require accounting for temperature changes between different dates) allow for inference of the dynamic component of the signal, based on the assumption that changes of ECa are related to changes in the volume of water in the soil pores and/or changes in the concentration of ions in the soil solutions.

Zhu et al. (2010) conducted repeated EMI measurements under varying moisture conditions on a 19.5 ha agricultural field in central Pennsylvania, and found that the spatial pattern of standardized ECa remained relatively stable over time. In their study, the $R^{2}$ values between ECa and $\theta$ measured at different depths varied between 0.24 and 0.47 . The authors argued that, because of the spatial heterogeneity of soil and hydrologic properties across the landscape, "the effect of soil moisture on ECa could have been masked by other variations of soil properties and terrain attributes". Soil ECa was strongly influenced by soil moisture during wetter periods and at wetter locations, whilst other factors masked the effect of soil moisture on ECa variations during drier periods and at drier locations. They also remarked that the relationship between temporal variations of the soil ECa and soil water dynamics has not been thoroughly investigated for different soil moisture conditions and drying-wetting cycles, because simultaneous soil moisture measurements and EMI surveys were conducted only three times in this study.

Martinez et al. (2010) measured soil ECa during 13 occasions over 3 years in Vertisols to map temporal changes of the spatial pattern of $\theta$. They used a principal component analysis to detect the main sources of variation of $\mathrm{ECa}$, and found that the EM38-DD could successfully identify changes in soil properties due to tillage (i.e., changes of soil porosity) and formation of cracks within the soil profile. In fact, the first three components (90\% of the ECa variability explained) were related to soil heterogeneity, soil management, and topography. Soil water dynamics reflected temporal variations of the above-mentioned factors, and could therefore be identified only as a less important signal.

Robinson et al. (2012) conducted EMI measurements on 9 occasions within 5 months in a small forested catchment with contrasting soil textures. Similar to the finding of Western et al. (2003), they found that two distinct patterns are present in the ECa and modeled $\theta$ maps: in the wet state, the spatial pattern of ECa correlated well with the spatial pattern of clay content, which, in turn, correlated well with $\theta$, whilst the pattern in the dry state shows a smaller degree of organization and reasonable uniformity in $\theta$ across the catchment. They proposed a differencing approach to estimate $\theta$ from $\mathrm{ECa}$, which improved the correlation from $R^{2}=0.28$ to $R^{2}=0.48$.

Recently, Shanahan et al. (2015) used repeated EMI measurements and electrical resistivity tomography to model soil $\mathrm{EC}$, combined with laboratory estimates of gravimetric soil water content $\left(\theta_{\mathrm{g}}\right)$, to investigate more specifically the effects of $\theta$ on EC in soils with contrasting texture and under different wheat genotypes. They documented difficulties of relating soil EC to $\theta_{\mathrm{g}}$; in fact, they observed that the correlation between changes in soil EC and changes in $\theta_{\mathrm{g}}$ varied with time and that the correlation was better for the investigated loamy sand soil than for the clay loam. The authors concluded that in soils where the effect of $\mathrm{EC}_{\mathrm{w}}$ appears to be larger, "changes in bulk EC, measured by EMI, may be confounded by increased pore water conductivity and less closely associated with changes in $\theta_{\mathrm{g}}$ ".

Findings of the studies summarized above clearly show the need for a more in-depth examination of the $\mathrm{ECa}-\theta$ relationship for soils under field conditions, with specific attention to the suite of physicochemical properties and states controlling the EMI measurements. The complexity of EMI data is too often ignored and the numerous issues related to the use of EMI for mapping of soil moisture are not always illustrated clearly. This may generate confusion due to the fact that proximal soil sensing techniques are used for a variety of scopes in several disciplines and there is a risk of interpreting ECa data beyond the limits of its applicability, resulting in misinterpretation.

This study aims to further investigate the potential of repeated EMI measurements with wide spatial coverage to capture field-scale soil water dynamics. To this end, we compare a time series of EMI measurements with high-resolution data from a wireless soil moisture and soil temperature monitoring network for a hillslope area in the Schäfertal catchment (Harz Mountains, central Germany), for which spatial soil properties and soil moisture dynamics are known in detail. This gives us the opportunity to discuss the complex interplay between factors controlling ECa and $\theta$, and the use of EMI-based ECa data with respect to hydrological applications.

\section{Material and methods}

\subsection{Site description}

The study was carried out on a hillslope at the Schäfertal experimental site, a small headwater catchment $\left(1.44 \mathrm{~km}^{2}\right)$ located in the Lower Harz Mountains, central Germany $\left(51^{\circ} 39^{\prime} \mathrm{N}, 11^{\circ} 03^{\prime} \mathrm{E}\right)$ (Borchardt, 1982; Reinstorf et al., 2010; Martini et al., 2015). The Schäfertal is a highly instrumented intensive research catchment within the TERENO "Harz/Central German Lowland observatory" (Zacharias et al., 2011; Wollschläger et al., 2017).

The catchment receives an average precipitation of $630 \mathrm{~mm}$ per year (of which a large fraction may be falling as snow, according to the annual winter conditions) and has an average annual air temperature of $6.9^{\circ}$. The slopes of the Schäfertal catchment are formed by Devonian argillaceous shales and greywackes of the so-called "Tanner Zone", which are covered by periglacial sediments (Borchardt, 1982). Cambisols and Luvisols are the dominant soil types on the slopes of the catchment, and Gleysols occupy the valley bot- 
tom (e.g., Ollesch et al., 2005). Interflow is known to play a relevant role within the runoff processes (Borchardt, 1982), and part of it can result in return flow. The slopes of the catchment are intensively used for agriculture, whilst meadow occupies the valley bottom (Schröter et al., 2015).

The hillslope site investigated for this study is a grassland transect beside the agricultural fields at the outlet of the catchment and consists of a north- and a south-exposed slope and a valley bottom where the creek Schäferbach lies (Fig. 1). The spatial extent is ca. $250 \mathrm{~m}$ by $80 \mathrm{~m}$. The detailed soil mapping for the Schäfertal hillslope site is described in Martini et al. (2015) and revealed low textural variations. The site is extensively managed, i.e., neither irrigation nor fertilizers are applied, which might alter $\mathrm{EC}_{\mathrm{w}}$ and effect the measured ECa. Overall, the site characteristics (low textural heterogeneity, extensive land use) and the experimental setup of the Schäfertal hillslope site provide a rare opportunity to assess the suitability of repeated EMI surveys for mapping soil moisture at the field scale.

\subsection{Hydropedological site characterization}

Intensive investigation of the vadose zone water dynamics on the hillslope (Martini et al., 2015) was recently conducted with the aid of a wireless soil moisture and soil temperature monitoring network (SoilNet; Bogena et al., 2010). The positions of the 40 measurement nodes of the network (Fig. 1) were determined by weighted Latin hypercube sampling with extremes (wecLHS, Schmidt et al., 2014) using information from geophysical surveys (EMI and gamma-ray spectroscopy) and topographic data. More detailed information can be found in Martini et al. (2015). For each of the network nodes, six sensors were permanently installed in the soil, with two repetitions at three depths $(5,25$, and $50 \mathrm{~cm})$, measuring soil moisture and soil temperature with hourly resolution. The sensors in use (SPADE, sceme.de GmbH i.G., Horn-Bad Meinberg, Germany; Hübner et al., 2009) are based on a ring oscillator. A sensor-specific seven-pointcalibration in reference media with well-known dielectric permittivity (Kögler et al., 2013) was conducted to improve the $\theta$ measurement accuracy. Additionally, a sensor-specific calibration was performed for the soil temperature sensors. Volumetric soil moisture content was estimated based on the CRIM formula according to Roth et al. (1990), where the dielectric permittivity of soil and air were assumed to be 4.6 and 1 , respectively, and the dielectric permittivity of water was calculated based on the measured soil temperature (Kaatze, 2007). Porosity was estimated using volumetric soil samples and ranged between 0.45 and 0.80 . More details can be found in Martini et al. (2015).

At each of the 40 sampling locations (Fig. 1), the soil profile was described down to the depth of ca. $0.60 \mathrm{~m}$ (at the ridgetop, stoniness of the soil due to shallow bedrock limited the investigation to ca. $0.50 \mathrm{~m}$ ), and the grain size distribution was determined for each node position and each soil hori-

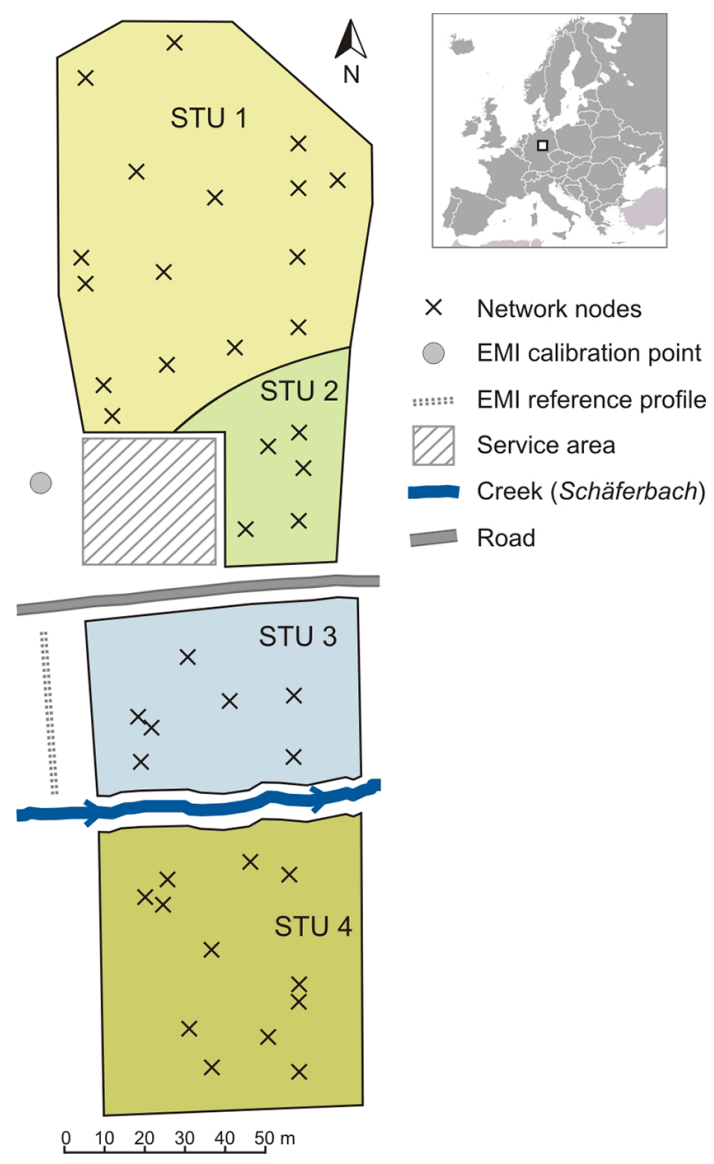

Figure 1. Schematic map of the Schäfertal hillslope site (Martini et al., 2015, modified): the position of the 40 nodes of the wireless soil moisture and soil temperature monitoring network is indicated, as well as the spatial extent of the four soil topographic units (STUs). EMI calibration point (grey dot) and reference profile (dashed line) are indicated in the eastern part of the hillslope.

zon. Four soil topographic units (STUs) were identified: silty loam Cambisols were found on the slopes (namely STU 1, STU 2 and STU 4), with few textural and morphological differences according to the topographic positions; characteristic hydromorphic features were identified in the valley bottom as indicators of the distinct wet state of the loam and silty loam stagnic Gleysols (STU 3), where soils are frequently water-saturated in winter and spring seasons. A summary of soil textural data relevant for the present work is provided in Table 1; additional details of the soil characteristics can be found in Martini et al. (2015).

The hydrological behavior of the Schäfertal hillslope site was characterized by Martini et al. (2015) using the daily average soil moisture values for each measurement point of the monitoring network at the depths of 5,25 , and $50 \mathrm{~cm}$ $\left(\theta_{\mathrm{d}, 05}, \theta_{\mathrm{d}, 25}\right.$, and $\theta_{\mathrm{d}, 50}$, respectively, also named topsoil, intermediate soil horizon, and deep soil horizon, as they refer to three distinct soil layers). The monitoring period (from 15 September 2012 to 14 November 2013) comprises dif- 

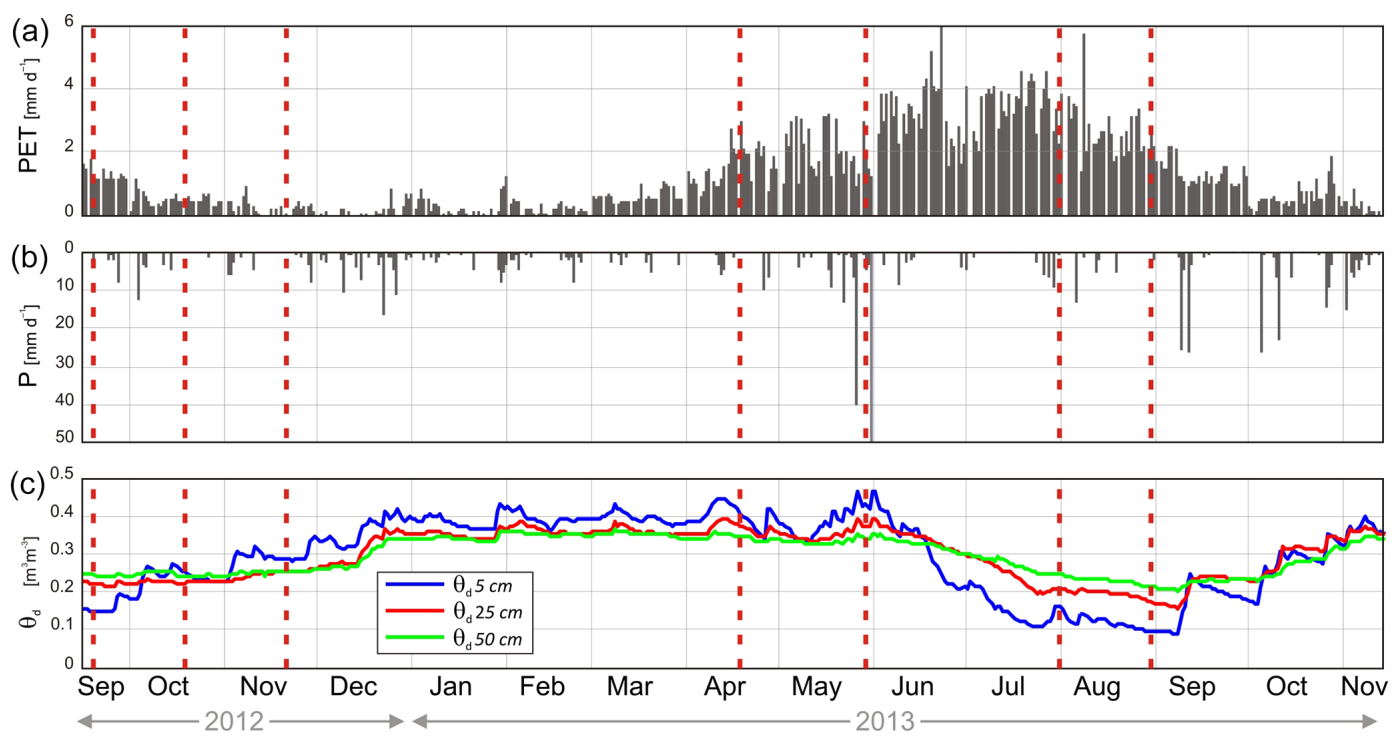

Figure 2. Time series of (a) daily potential evapotranspiration (PET), (b) daily cumulative precipitation $(P)$, and (c) daily average soil moisture at the three depths of observation $\left(\theta_{\mathrm{d}, 05}, \theta_{\mathrm{d}, 25}\right.$, and $\theta_{\mathrm{d}, 50}$, respectively). Vertical dotted lines indicate the dates of the EMI measurements: 19 September 2012, 18 October 2012, 20 November 2012, 18 April 2013, 28 May 2013, 31 July 2013, and 29 August 2013 (Martini et al., 2015, modified)

Table 1. Soil texture (median values) of the Schäfertal hillslope site for the topsoil (ca. $0-15 \mathrm{~cm}$ ) and for the subsoil (ca. $15-60 \mathrm{~cm}$ ). More detailed information can be found in Martini et al. (2015).

\begin{tabular}{rlccr}
\hline \multicolumn{2}{c}{ Soil } & \% Clay & \% Silt & \% Sand \\
\hline \multirow{2}{*}{ STU 1 } & topsoil & 17 & 69 & 14 \\
& subsoil & 15 & 67 & 18 \\
\hline \multirow{2}{*}{ STU 2 } & topsoil & 16 & 78 & 7 \\
& subsoil & 15 & 79 & 6 \\
\hline \multirow{2}{*}{ STU 3 } & topsoil & 25 & 67 & 10 \\
& subsoil & 14 & 55 & 28 \\
\hline \multirow{2}{*}{ STU 4 } & topsoil & 15 & 77 & 9 \\
& subsoil & 13 & 76 & 12 \\
\hline
\end{tabular}

ferent states of soil moisture in response to varying atmospheric conditions (Fig. 2). Soil moisture increased during the fall of 2012, when rainfall events were frequent and evapotranspiration (ET) decreased. The winter season was characterized by low precipitation $(P)$ and low ET, followed by the spring season (April to June 2013), dominated by strong dynamics of soil moisture in response to increasing ET and extreme rainfalls up to $49 \mathrm{~mm} \mathrm{day}^{-1}$. Large areas of central Europe were flooded at that time, and soils at the Schäfertal site were observed to be saturated in swales and depressions. During the summer period, ET exceeded $P$ and the soil remained drier than the annual mean. The wetting transition started at the beginning of September 2013, with intense rainfalls and decreasing ET.

\subsection{Repeated soil-ECa mapping}

In the last decades, a number of sensors were developed for field measurements of ECa, based on the electromagnetic induction theory (Keller and Frischknecht, 1966). Technically, a transmitter and a receiver coil are placed on (or near) the soil surface at a fixed distance from each other, and the transmitter coil is energized with an alternating current. This generates a time-varying magnetic field, which induces electric fields in the soil, which in turn induce a secondary magnetic field. Such phenomena are described by Ampere's and Maxwell's laws. Both the primary and the secondary magnetic fields are sensed by the receiver coil and, under certain geometric conditions indicated as "low induction number" (McNeill, 1980; Callegary et al., 2007, 2012), the ratio between the primary and the secondary magnetic field can be used to estimate the $\mathrm{ECa}$ of the volume of soil under investigation.

Generally, EMI systems consist of a transmitter and a receiver coil spaced $s$ and operating at a certain frequency $f$. As $s$ increases, the EM field propagates through a larger volume of soil. As $f$ increases, the EM field is more attenuated and therefore penetrates less into the soil, reducing the volume of investigation. Transmitter and receiver coils are commonly adjusted in coplanar configuration. Vertical coplanar coils (VCP) generate a horizontal magnetic dipole orientation (HDP), whilst the horizontal coplanar coil configuration (HCP) generates a vertical magnetic dipole (VDP). The coil configuration has implications for the volume of investigation. McNeill (1980) provided the relative response versus depth for an EMI device in both HDP and VDP and the "cu- 
mulative response" for homogeneous and layered soils. According to that, the response of an EMI device in HDP has larger sensitivity close to the soil surface (or, more precisely, immediately below the coils), with monotonic decay with depth, whilst the VDP configuration provides maximum sensitivity to the depth of ca. $0.4 \cdot s$ (i.e., $40 \%$ of the inter-coil spacing $s$ ). Additionally, the effective depth of exploration, defined as the portion that contributes with $70 \%$ to the measured value of $\mathrm{ECa}$, is $0.75 \cdot s$ for the HDP and $1.50 \cdot s$ for the VDP configuration.

For this study, soil ECa was measured using an EM38-DD device (Geonics Ltd., Ontario, Canada), widely used for environmental studies and hence severely tested under various conditions. The system is composed of two units mounted perpendicularly to each other, both consisting of a transmitter and a receiver coil $(s=1 \mathrm{~m})$, which allows simultaneous measurements of ECa over two depths for every measurement location. In VDP, given the operating frequency $f=14.5 \mathrm{kHz}$, the theoretical maximum sensitivity corresponds to the depth of ca. $0.40 \mathrm{~m}$ and the theoretical maximum investigation depth to ca. $1.50 \mathrm{~m}$. In $\operatorname{HDP}(f=17 \mathrm{kHz})$, the sensitivity of the device decreases with depth down to a theoretical maximum depth of investigation of ca. $0.75 \mathrm{~m}$ (McNeill, 1980).

Surveys were conducted on seven measurement dates within the soil moisture monitoring period (Fig. 2), with three measurement dates (19 September, 18 October and 20 November 2012) during the wetting transition; two dates (18 April and 28 May 2013) during the dynamic spring period; and two dates (31 July and 29 August 2013) during the dry summer season. The surveys were conducted with the EMI device mounted on a sledge (made of wood and plastic, in order to avoid conductivity anomalies) at ca. $0.05 \mathrm{~m}$ above ground and pulled by one operator at constant walking speed. The study area was divided into three fields: northern slope (i.e., STUs 1 and 2), valley bottom (i.e., STU 3) and southern slope (i.e., STU 4), and each field was measured separately. A fixed location next to the study area (Fig. 1), was used as calibration point for instrument nulling (McNeill, 1980) before each survey, and according to the recommendations of, e.g., Robinson et al. (2004), a warm-up period of at least $30 \mathrm{~min}$ was ensured before measurements were started. Before and after the surveys, ECa was measured along the reference profile (i.e., a fixed $40 \mathrm{~m}$ transect, Fig. 1) in order to assess and correct a possible drift in the data (e.g., Sudduth et al., 2001; Abraham et al., 2006). ECa was measured along survey lines spaced ca. $5 \mathrm{~m}$ apart with a rate of 5 records $\mathrm{s}^{-1}$, resulting in an approximate resolution of $0.2 \mathrm{~m}$ along the main direction. Towards the end of each of the surveys, crossing lines (Simpson et al., 2009) were measured in order to use the crossover points for drift correction (CWA 16373, 2011; Delefortrie et al., 2014).

\subsection{Processing and integration of time-lapse ECa measurements}

Data collected using the HDP configuration showed strong noise. This caused critical problems in data processing and hindered a purposeful data interpretation. As the datasets of ECa measured in VDP did not show significant noise or drift, only those data were used for the present work.

Similar to Rudolph et al. (2016), data points located within a $2 \mathrm{~m}$ circular buffer area around each of the soil moisture monitoring network nodes were removed in order to exclude any possible data alteration induced by the magnetic components of the network nodes. By plotting the measured ECa data over time, a limited number of additional outliers could be identified as isolated extreme and unrealistic values.

Data collected with EMI devices may be affected by drift due to instability of the calibration or to temperature changes (Robinson et al., 2004). The measured crossing lines were used to identify and correct the drift: with the help of the interfaces of normal profiles and crossing-lines, a linear drift function was derived for the datasets which required this and was used for drift correction. On average, the observed drift was as low as $1.14 \mathrm{mS} \mathrm{m}^{-1}$. In this step, we assumed that $\mathrm{ECa}$ along the reference profile remains constant during the time of the survey, i.e., ca. $45 \mathrm{~min}$ for the south-facing slope (STU 1 and STU 2 in Fig. 1), ca. 15 min for the valley bottom (STU 3) and ca. $30 \mathrm{~min}$ for north-facing slope (STU 4), hence the reference profile measured at the beginning and at the end of each of the surveys must show similar values of ECa.

Due to the sensor nulling performed prior to each survey, a small offset may occur between the datasets collected at different measurement dates, e.g., because of differences in weather conditions which may affect the measurement signal (e.g., Triantafilis et al., 2000). For this reason, we refrain from comparing absolute values from different measurement dates in this study and concentrate (i) on the analysis of differences in spatial patterns of $\theta$ and ECa identified using the Spearman rank correlation coefficient and (ii) on differences in the relationship between ECa and $\theta$ for the individual measurement dates. By doing so, we are well able to discuss the data in terms of hydrological processes and do not attempt to quantify temporal changes of $\theta$ from the EMI measurements, which would not be supported by the dataset.

ECa data measured along the reference profile for the same day were plotted against time and, if necessary, field data were corrected by applying a shift (on average as low as $0.86 \mathrm{mS} \mathrm{m}^{-1}$ ) based on the mean ECa of the reference profiles. We tested that this did not produce artifacts in the spatial pattern of ECa. Based on the assumption that ECa along the reference profile does not vary within the duration of the measurement (i.e., a few hours), such a procedure ensured the data collected with different surveys within the same day to be quantitatively comparable. Measured ECa data were standardized to the reference temperature of $25^{\circ} \mathrm{C}$ using the correction factors provided by U.S.D.A. (1954). Three dif- 
ferent reference soil temperatures were calculated (one for the valley bottom and one for each of the two slopes with opposite exposition) averaging all available temperature values measured hourly at the depths of 25 and $50 \mathrm{~cm}$ between 09:00 and 16:00 LT on each EMI measurement date (i.e., the time frame in which the surveys were carried out). Except for the topsoil, temperature variations within such time intervals are negligible. Among the different measurement dates, the lowest soil temperature was recorded for the EMI survey in November 2012 (i.e., $4^{\circ} \mathrm{C}$ on the south-exposed hillslope), and the highest in July 2013 (i.e., $19^{\circ} \mathrm{C}$ in the valley bottom).

For each measurement date and for each independent dataset, the experimental variogram was calculated for the temperature-corrected ECa and fitted using a linear model for comparability. The fitting parameters were used to interpolate the data using block kriging with a cell size of $1 \mathrm{~m}$. The choice of using linear variogram models was supported by the fact that, despite not all experimental variograms showing a linear behavior at larger lag distances, linear behavior is always given for the $1 \mathrm{~m}$ distance used later on for interpolation (data not shown). Afterwards, for each measurement date, the three datasets for the northern slope, the valley bottom, and the southern slope were aggregated, and ECa values of the kriging cell corresponding to the location of each network node were extracted for each measurement date, similar to Zhu et al. (2010). For the following analysis, extracted $\mathrm{ECa}$ values $\left(\mathrm{ECa}_{\mathrm{e}}\right)$ for the seven measurement dates were used in combination with the daily-averaged soil moisture $\left(\theta_{\mathrm{d}}\right)$ at the depths of 5,25 , and $50 \mathrm{~cm}$ (based on the available hourly measurements between 09:00 and 16:00 LT) at each single network node for the same measurement dates. As the two methods refer to very different measurement volumes (i.e., integrated ECa values from EMI versus local soil moisture estimation from the SPADE sensors which compose the monitoring network), an integrated soil moisture value $\left(\theta_{\mathrm{d}, \mathrm{CS}}\right)$ was calculated for every measurement date and for every node of the monitoring network:

$\theta_{\mathrm{d}, \mathrm{CS}}=\sum_{i=1}^{n} \frac{\theta_{n}\left[\operatorname{CS}\left(z_{i-1}\right)-\operatorname{CS}\left(z_{i}\right)\right]}{\sum_{i=1}^{n} \operatorname{CS}\left(z_{i}\right)}$,

where $\theta_{n}$ are the soil moisture measurements at the three depths of monitoring and $\operatorname{CS}\left(z_{i}\right)$ refers to the cumulative sensitivity function of the EMI (McNeill, 1980).

Although this simple approach neglects vertical changes of soil properties within the soil profile (i.e., soil horizons which may affect the vertical distribution of $\theta$ ), we assume that the integrated soil moisture values $\theta_{\mathrm{d}, \mathrm{CS}}$ provide representative information about the weighted $\theta$ within the volume of soil sensed by the EMI device.

\subsection{Analysis of the temporal stability of soil moisture and ECa patterns}

The Spearman rank correlation coefficient was used to investigate the temporal stability of the spatial pattern of $\mathrm{ECa}_{\mathrm{e}}$ and $\theta_{\mathrm{d}}$ over the seven dates of survey. This coefficient was proposed by Vachaud et al. (1985) as a measure of similarity between two datasets, based on the comparison of the rank of spatially distributed observations between two times, and is defined as follows:

$r_{\mathrm{S}}\left(j_{1} j_{2}\right)=\frac{6 \sum_{i=1}^{N}\left[R\left(i, j_{1}\right)-R\left(i, j_{2}\right)\right]^{2}}{\left(N_{\mathrm{s}}-1\right) N s\left(N_{\mathrm{s}}+1\right)}$,

where $N_{\mathrm{S}}$ is the total number of spatial observation locations, $R\left(i, j_{1}\right)$ is the rank of the observation for the position $i$ and for the time $j_{1}$, and $R\left(i, j_{2}\right)$ is the rank of the observation for the same position, but for the time $j_{2}$. The $r_{\mathrm{s}}$ coefficient ranges between -1 and 1 , and describes the statistical dependence between the two ranked variables: $r_{\mathrm{s}}=1$ when there are no changes in the rank of the observations and decreases proportionally to the number of observations for which the rank varies and the number of position changed both toward a higher or lower rank. In other words, the Spearman rank correlation coefficient shows the qualitative similarity between spatially distributed observations.

\section{Results and discussion}

\subsection{Observed spatial patterns of ECa and soil moisture}

In contrast to results from other sites (Martinez et al., 2010; Robinson et al., 2012; Lausch et al., 2013; Martini et al., 2013), ECa measured on the Schäfertal hillslope was low, ranging between 0 and $24 \mathrm{mS} \mathrm{m}^{-1}$ during the complete measurement period and showed a very small range of spatial variation, which we attribute predominantly to the small heterogeneity of soil texture. The range in $\mathrm{ECa}_{\mathrm{e}}$ measured along the slopes varied between $7.6 \mathrm{mS} \mathrm{m}^{-1}$ in August 2013 and $11.8 \mathrm{mS} \mathrm{m}^{-1}$ in November 2013. This small range makes the interpretation of the dynamics in ECa challenging. Nevertheless, the low soil textural variation along the slopes provides the opportunity to evaluate the effect of soil moisture on the measured ECa without the need to account for significant influences of soil texture.

For the seven measurement dates, the overall spatial pattern of measured ECa as well as the extracted apparent electrical conductivity at the positions of the network nodes $\left(\mathrm{ECa}_{\mathrm{e}}\right)$ showed highest values in the valley bottom (STU 3) and on the footslope (STU 2), whereas the hillslopes (STU 1 and STU 4) showed lower values (Fig. 3a and b). Similar spatial patterns were observed for soil moisture (Fig. 3c-e) at the three depths of monitoring. Absolute values of measured ECa were lowest in September 2012, 


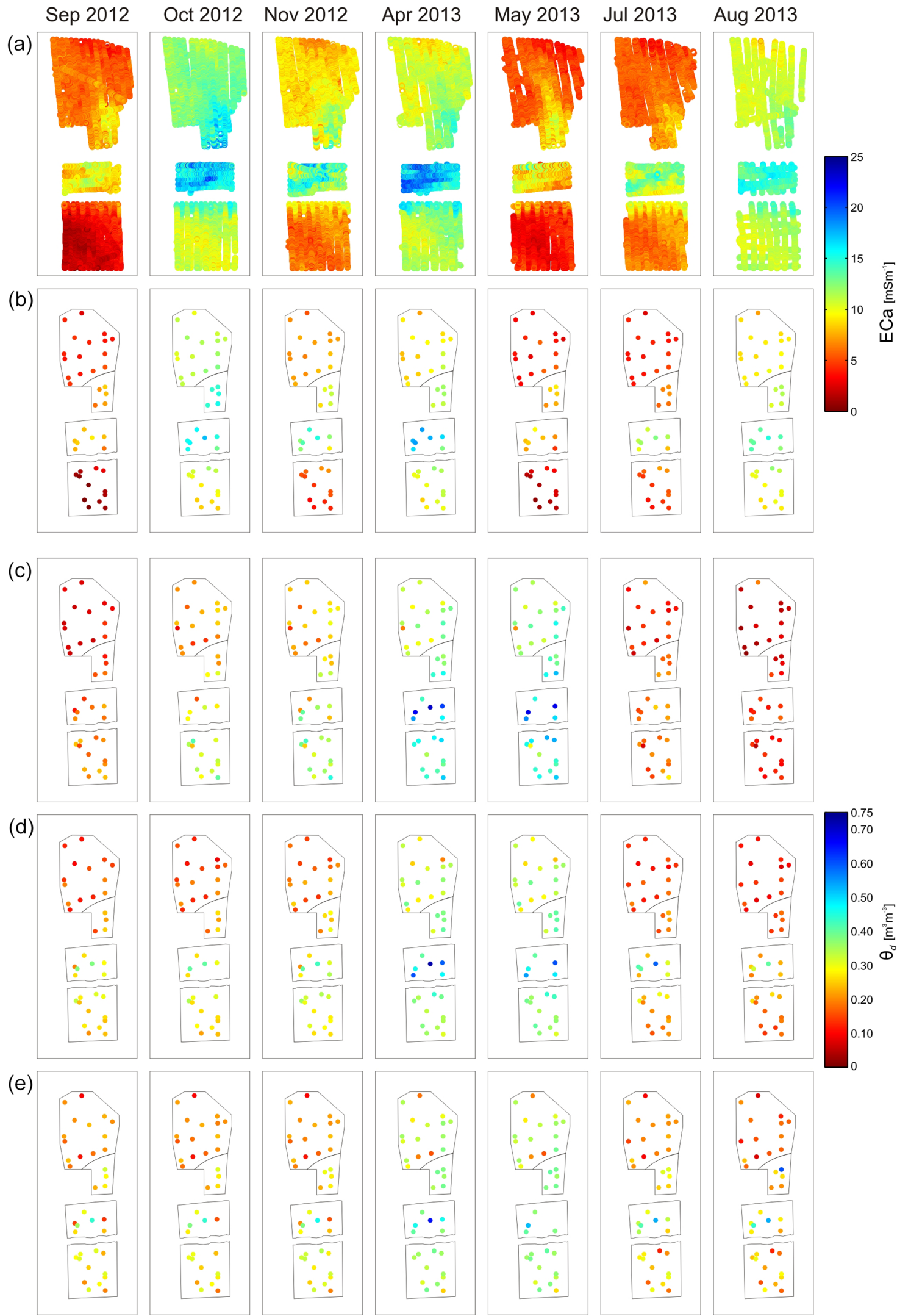

Figure 3. Spatial maps of (a) measured ECa (after processing); (b) extracted apparent electrical conductivity (ECa $)$ for the positions of the 40 nodes of the soil moisture monitoring network; (c) daily mean soil moisture at $5 \mathrm{~cm}\left(\theta_{\mathrm{d}, 05}\right)$; (d) daily mean soil moisture at $25 \mathrm{~cm}\left(\theta_{\mathrm{d}, 25}\right)$; (e) daily mean soil moisture at $50 \mathrm{~cm}\left(\theta_{\mathrm{d}, 50}\right)$. 
Table 2. Spearman rank correlation coefficients $\left(r_{\mathrm{s}}\right)$ between spatial patterns of ECa . Values of $r_{\mathrm{s}} \geq 0.9$ are highlighted in bold.

\begin{tabular}{lrrrrrrr}
\hline & Sep 2012 & Oct 2012 & Nov 2012 & Apr 2013 & May 2013 & Jul 2013 & Aug 2013 \\
\hline Sep 2012 & $\mathbf{1}$ & & & & & & \\
Oct 2012 & $\mathbf{0 . 9 4}$ & $\mathbf{1}$ & & & & & \\
Nov 2012 & $\mathbf{0 . 9 8}$ & $\mathbf{0 . 9 6}$ & $\mathbf{1}$ & & & & \\
Apr 2013 & 0.54 & 0.66 & 0.60 & $\mathbf{1}$ & & & \\
May 2013 & $\mathbf{0 . 9 5}$ & $\mathbf{0 . 9 4}$ & $\mathbf{0 . 9 3}$ & 0.59 & $\mathbf{1}$ & & \\
Jul 2013 & 0.55 & 0.66 & 0.59 & $\mathbf{0 . 9 7}$ & 0.58 & $\mathbf{1}$ & \\
Aug 2013 & 0.55 & 0.67 & 0.61 & $\mathbf{0 . 9 6}$ & 0.58 & $\mathbf{0 . 9 8}$ & $\mathbf{1}$ \\
\hline
\end{tabular}

Table 3. Spearman rank correlation coefficients $\left(r_{\mathrm{s}}\right)$ between spatial patterns of soil moisture $\left(\theta_{\mathrm{d}, 05}\right)$ in the topsoil. Values of $r_{\mathrm{s}} \geq 0.9$ are highlighted in bold.

\begin{tabular}{lrrrrrrr}
\hline & Sep 2012 & Oct 2012 & Nov 2012 & Apr 2013 & May 2013 & Jul 2013 & Aug 2013 \\
\hline Sep 2012 & $\mathbf{1}$ & & & & & & \\
Oct 2012 & 0.85 & $\mathbf{1}$ & & & & & \\
Nov 2012 & 0.84 & $\mathbf{0 . 9 5}$ & $\mathbf{1}$ & & & & \\
Apr 2013 & 0.80 & 0.73 & 0.79 & $\mathbf{1}$ & & & \\
May 2013 & 0.73 & 0.66 & 0.74 & $\mathbf{0 . 9 9}$ & $\mathbf{1}$ & & \\
Jul 2013 & 0.67 & 0.63 & 0.61 & 0.67 & 0.65 & $\mathbf{1}$ & \\
Aug 2013 & 0.62 & 0.54 & 0.56 & 0.70 & 0.70 & 0.83 & $\mathbf{1}$ \\
\hline
\end{tabular}

May and July 2013 and highest in October 2012, April, and August 2013.

For the dates of the EMI surveys, the overall spatial distribution of soil moisture measured at the nodes of the monitoring network showed similar distributions (Fig. 3c-e), with the lowest $\theta_{\mathrm{d}}$ being measured in summit and backslope positions of the south-exposed slope, and highest $\theta_{\mathrm{d}}$ in the valley bottom. The topsoil's daily average moisture $\left(\theta_{\mathrm{d}, 05}\right)$ exhibited the largest temporal variability, with overall hillslope minimum in September 2012 and July and August 2013 (i.e., $0.15,0.16$, and $0.10 \mathrm{~m}^{3} \mathrm{~m}^{-3}$, respectively; Fig. 2) and maximum in April and May 2013 (i.e., 0.41 and $0.43 \mathrm{~m}^{3} \mathrm{~m}^{-3}$, respectively). Daily average soil moisture of the intermediate soil horizon $\left(\theta_{\mathrm{d}, 25}\right)$ ranged between 0.17 (measured in August 2013) and $0.37 \mathrm{~m}^{3} \mathrm{~m}^{-3}$ (in April and May 2013). The deep soil horizon showed less variable daily average soil moisture ranging between 0.23 and $0.25 \mathrm{~m}^{3} \mathrm{~m}^{-3}$ except for the measurement dates of April and May 2013 $\left(\theta_{\mathrm{d}, 50}=0.35 \mathrm{~m}^{3} \mathrm{~m}^{-3}\right)$.

The fact that, during the monitoring period, soil moisture values covered the complete annual range from very dry (in August 2013) to near-saturation (in May 2013), while few variations were observed in the range and absolute values of $\mathrm{ECa}$ for the different measurement dates, gives a first, strong indication that, for the Schäfertal hillslope site, soil moisture has little influence on the measured ECa.

\subsection{Temporal persistence of the spatial patterns}

To further analyze the temporal persistence of the generally similar spatial patterns of ECa and soil moisture, the Spearman rank correlation coefficient $\left(r_{\mathrm{s}}\right)$ was used. To this end, we investigated the temporal persistence of the spatial pattern of $\mathrm{ECa}_{\mathrm{e}}$ as well as the temporal persistence of the spatial pattern of $\theta_{\mathrm{d}}$ at the three depths of observation. The overall spatial pattern of $\mathrm{ECa}_{\mathrm{e}}$ exhibited a similar distribution for all measurement dates (higher values in the valley bottom, lower values on the slopes), whilst the spatial organization of the values within the site showed some differences. Two distinct spatial patterns (Table 2, $r_{\mathrm{s}} \geq 0.9$ ) of $\mathrm{ECa}_{\mathrm{e}}$ were highlighted: one being present in September, October, and November 2012 and May 2013, and another one in April, July, and August 2013.

The spatial pattern of soil moisture in the topsoil $\left(\theta_{\mathrm{d}, 05}\right)$ showed low persistence with $r_{\mathrm{s}}$ decreasing proportionally to the time between two measurement dates (Table 3). The intermediate and deep soil horizons $\left(\theta_{\mathrm{d}, 25}\right.$ and $\theta_{\mathrm{d}, 50}$; Tables 4 and 5) showed a similar evolution of the pattern, however, as expected, with higher persistence than observed for the topsoil moisture. Three groups $\left(r_{\mathrm{s}} \geq 0.9\right)$ of spatial distribution could be identified: (i) transition from dry to wet state (September, October, and November 2012); (ii) wet state (April and May 2013); and (iii) dry state (July and August 2013).

The direct comparison of the spatial patterns of $\mathrm{ECa}_{\mathrm{e}}$ and $\theta_{\mathrm{d}}$ showed a clear difference for all three measurement depths. This again supports the observation that, for the 
Table 4. Spearman rank correlation coefficients $\left(r_{\mathrm{s}}\right)$ between spatial patterns of soil moisture $\left(\theta_{\mathrm{d}, 25}\right)$ in the intermediate soil horizon. Values of $r_{\mathrm{S}} \geq 0.9$ are highlighted in bold.

\begin{tabular}{lrrrrrrr}
\hline & Sep 2012 & Oct 2012 & Nov 2012 & Apr 2013 & May 2013 & Jul 2013 & Aug 2013 \\
\hline Sep 2012 & $\mathbf{1}$ & & & & & & \\
Oct 2012 & $\mathbf{0 . 9 7}$ & $\mathbf{1}$ & & & & & \\
Nov 2012 & $\mathbf{0 . 9 5}$ & $\mathbf{0 . 9 9}$ & $\mathbf{1}$ & & & & \\
Apr 2013 & 0.81 & 0.81 & 0.81 & $\mathbf{1}$ & & $\mathbf{1}$ & \\
May 2013 & 0.80 & 0.80 & 0.80 & $\mathbf{0 . 9 9}$ & 0.80 & $\mathbf{1}$ & \\
Jul 2013 & 0.86 & 0.88 & 0.82 & 0.80 & 0.76 & $\mathbf{0 . 9 9}$ & $\mathbf{1}$ \\
Aug 2013 & 0.87 & 0.88 & 0.83 & 0.76 & & & \\
\hline
\end{tabular}

Table 5. Spearman rank correlation coefficients $\left(r_{\mathrm{s}}\right)$ between spatial patterns of soil moisture $\left(\theta_{\mathrm{d}, 50}\right)$ in the deep soil horizon. Values of $r_{\mathrm{S}} \geq 0.9$ are highlighted in bold.

\begin{tabular}{lrrrrrrr}
\hline & Sep 2012 & Oct 2012 & Nov 2012 & Apr 2013 & May 2013 & Jul 2013 & Aug 2013 \\
\hline Sep 2012 & $\mathbf{1}$ & & & & & & \\
Oct 2012 & $\mathbf{0 . 9 9}$ & $\mathbf{1}$ & & & & & \\
Nov 2012 & $\mathbf{0 . 9 6}$ & $\mathbf{0 . 9 8}$ & $\mathbf{1}$ & & & & \\
Apr 2013 & 0.68 & 0.63 & 0.65 & $\mathbf{1}$ & & $\mathbf{1}$ & \\
May 2013 & 0.75 & 0.73 & 0.74 & $\mathbf{0 . 9 7}$ & 0.69 & $\mathbf{1}$ & \\
Jul 2013 & 0.63 & 0.82 & 0.63 & 0.72 & 0.64 & $\mathbf{0 . 9 6}$ & $\mathbf{1}$ \\
Aug 2013 & 0.67 & 0.84 & 0.65 & 0.69 & & & \\
\hline
\end{tabular}

Schäfertal hillslope site, soil moisture has little influence on the measured ECa.

\subsection{Correlation between ECa and soil moisture at the measurement node positions}

Figure 4 shows the relationship between $\mathrm{ECa}_{\mathrm{e}}$ and $\theta_{\mathrm{d}}$ for the different EMI measurement dates and depths of soil moisture monitoring. The plots in the bottom panels relate $\mathrm{ECa}_{\mathrm{e}}$ to the $\theta$ values calculated based on the cumulative sensitivity function $\left(\theta_{\mathrm{d}, \mathrm{CS}}\right)$ proposed by McNeil (1980). As discussed earlier in the text, intrinsic limitations exist in the EMI measurement technique which may limit the comparability of absolute ECa values; thus we did not attempt to interpret the temporal changes of $\mathrm{ECa}_{\mathrm{e}}$ from one measurement date to the other, but rather we focus on the $\mathrm{ECa}_{\mathrm{e}}-\theta_{\mathrm{d}}$ relationship for every single measurement date and depth of monitoring which, however, provides useful hints about the strength and persistence of the relationship.

Taking a closer look at the $\mathrm{ECa}-\theta$ relationship shown in Fig. 4 , the topsoil moisture $\left(\theta_{\mathrm{d}, 05}\right)$ generally showed an overall poor correlation with ECa, with the exception of the survey in April 2013. Nevertheless, the EM38-DD in VDP has little sensitivity to shallow structures (Callegary et al., 2007, 2012; McNeil, 1980). For the depths of 25 and $50 \mathrm{~cm}$, very poor correlation was found during the wetting transition (i.e., September, October, and November 2012, with $p>0.05$ ) and for May 2013. Better correlation was found for the measurements in April 2013 and in the dry state (July and August 2013). In particular, $R^{2}>0.50$ was found for the $\mathrm{ECa}_{\mathrm{e}}-$ $\theta_{\mathrm{d}}$ relationship for both the intermediate and the deep soil moisture measurements in April and July 2013, as well as for the $25 \mathrm{~cm}$ depth in August 2013. The same is well summarized by the $E C a_{e}-\theta_{d, C S}$ relationship, as expected. Overall, when the entire hillslope area is considered, $\mathrm{ECa}_{\mathrm{e}}$ was observed to show some correlation with $\theta_{\mathrm{d}}$ for only one of the two measurement dates in the wet state and on both measurement dates in the dry state. Nevertheless, no unique correlation between $\mathrm{ECa}_{\mathrm{e}}$ and $\theta_{\mathrm{d}}$ could be identified for the complete time series, which clearly shows that $\mathrm{ECa}_{\mathrm{e}}$ cannot be used as a proxy for quantitative spatial soil moisture distribution at the investigated site.

Deeper insights into the factors controlling the temporal dynamics of the $\mathrm{ECa}_{\mathrm{e}}-\theta_{\mathrm{d}}$ relationship can be gained by considering the relative position of the point clouds of the four STUs (represented with different colors in Fig. 4). The fact that measurement points within the same STU clustered within a limited region of the scatter plot illustrates the rather low within-STU variability of the soil bulk electrical conductivity at the site.

For some of the measurement dates, the point clouds of the different STUs occupied different positions relative to each other following changes of ECa and, especially, $\theta$. A distinction, in terms of moisture content, can be observed (Fig. 4) between the soils on the slopes (STU 1 and STU 4, southand north-exposed, respectively, but with similar soil texture), which can be referred to differences of ET on the northand south-exposed slopes leading to lower ET and higher soil moisture values for the north-exposed STU 4. Such an ef- 

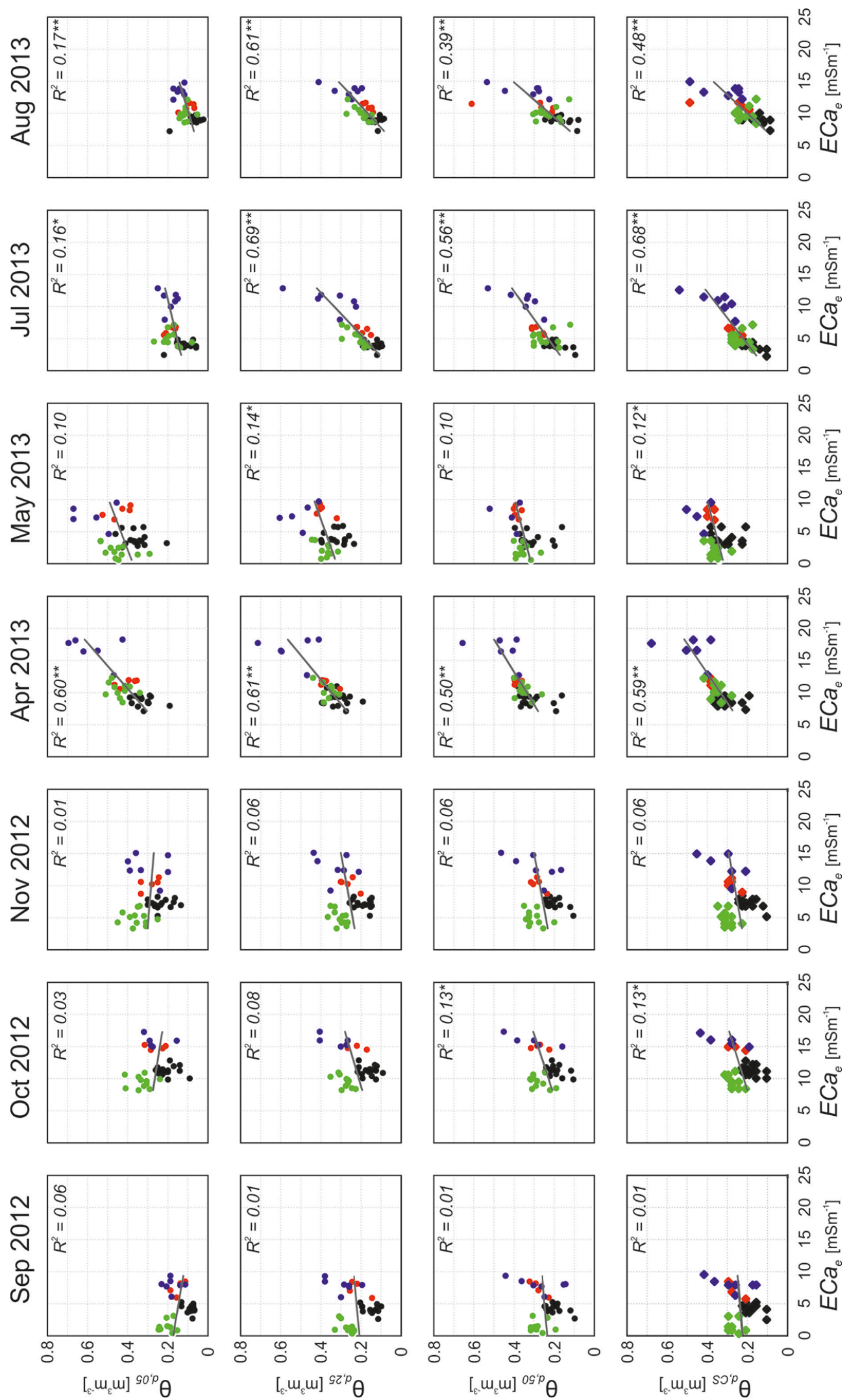

Figure 4. Linear regression between $\mathrm{ECa}_{\mathrm{e}}$ and $\theta_{\mathrm{d}}$ for every EMI measurement date and every depth of soil moisture monitoring $\left(\theta_{\mathrm{d}, 05}, \theta_{\mathrm{d}, 25}\right.$ and $\theta_{\mathrm{d}, 50}$, respectively), as well as for the integrated soil moisture calculated using the cumulative sensitivity function $\left(\theta_{\mathrm{d}, \mathrm{CS}}\right)$. The different colors represent measurement points located within: STU 1 - black dots; STU 2 - red dots; STU 3 - blue dots; and STU 4 - green dots. Regression coefficients $R^{2}$ are indicated; the significance levels $p<0.05$ and $p<0.01$ are indicated as ${ }^{*}$ and ${ }^{* *}$, respectively. 
fect was evident at the beginning of the monitoring period (measurement date in September 2012) as the result of the summer period during which ET is presumed to have led to persistently different moisture values, which remained visible during the rest of the wetting transition (October and November 2012). Similarly, the two measurement dates in the dry season (July and August 2013) showed higher $\theta_{\mathrm{d}}$ values for STU 4 than for STU 1 at all depths of measurement. ET is also presumed to have had important effects on the topsoil moisture in the valley bottom $\theta_{\mathrm{d}, 05}$, blue dots in Fig. 4), which has high porosity and remained rather dry in the summer period. This circumstance was inferred as favorable for the occurrence of preferential flow through the topsoil in the valley bottom (STU 3) at the end of the dry seasons in 2012 and 2013 (Martini et al., 2015). Higher $\theta_{\mathrm{d}}$ compared to the slopes persisted in the valley bottom during the winter period, due to the combination of local soil properties (i.e., higher porosity), topographic position and the presence of a shallow groundwater table. In particular, the latter allowed the soil to reach saturation in the valley bottom, locally, according to the local topographic features. This is evident in Fig. 4 for the measurement date in April 2013, represented by five network nodes (out of seven in STU 3, blue dots) which are now well separated from the rest of the data points showing soil moisture values as high as $0.72 \mathrm{~m}^{3} \mathrm{~m}^{-3}$. At the same time, the groundwater-distant soils on the slopes received water only from snowmelt and from rainfall. The flood event with strong rainfall at the end of May 2013 is responsible for the overall high $\theta_{\mathrm{d}}$ measured at the site. Large areas within the valley bottom were saturated due to shallow groundwater level, and patches of ponding water were observed; local emergence of return flow was observed at footslope positions within the catchment. In the summer period (measurement dates in July and August 2013 in Fig. 4), ET plays an important role in conjunction with local soil properties. Thus, the different moisture content between the soils on opposite slopes (STU 1 and 4) is visible, as well as the higher $\theta_{\mathrm{d}}$ in the subsoil in the valley bottom (STU 3).

Based on this, the three distinct spatial patterns of soil moisture observed in Tables 3-5 can be attributed to distinct factors: local soil properties and ET in the dry state (July and August 2013); local soil properties, topography, and a shallow groundwater table in the wet state (April and May 2013); and local soil properties, progressive reduction of ET and progressive rise of the groundwater table in the valley bottom during the transition from dry to wet (September, October, and November 2012).

In a similar manner, the two distinct spatial patterns of $\mathrm{ECa}_{\mathrm{e}}$ (Table 2) can be discussed referring to Fig. 4. Under dry soil conditions (July and August 2013), the higher ECa measured in the valley bottom (STU 3) compared to the slopes can be attributed to the presence of loam and silty loam stagnic Gleysols, with finer texture and high organic matter content. The silty loam Cambisols on the slopes (STU 1, 2, and 4) showed similar values of ECa in response to overall similar textural characteristics. In April 2013, an important contribution to the high moisture content on the slopes came from snowmelt. Thus, a large volume of water within the volume of soil sensed by the EMI device was likely to have low $\mathrm{EC}_{\mathrm{w}}$ leading to overall low $\mathrm{ECa}_{\mathrm{e}}$ values being comparable to the dry state, when the pores were air-filled. Furthermore, the influence of more conductive water (from groundwater which drains the fertilized agricultural fields of the Schäfertal catchment) enhanced the higher $\mathrm{ECa}_{\mathrm{e}}$ values for the valley bottom compared to the slopes. This is evident from the gap, in terms of $\mathrm{ECa}_{\mathrm{e}}$, between the blue dots and all other points in Fig. 4. As a consequence, the spatial pattern of $\mathrm{ECa}_{\mathrm{e}}$ for the measurement date in April 2013 was substantially similar to the spatial pattern observed in the dry season (Table 2). This is not the case for the measurement date in May 2013, when there was no contribution of water from snowmelt. As a consequence, a higher concentration of ions in the soil solution can be assumed, causing a higher $\mathrm{EC}_{\mathrm{w}}$ that is presumed to have contributed significantly to the bulk soil electrical conductivity for the entire study area, with the effect of masking the textural differences between the valley bottom and the slopes. Therefore, the spatial pattern of $\mathrm{ECa}_{\mathrm{e}}$ for the measurement date in May 2013 did not reflect those of July, August, and April 2013. Similarly, the spatial pattern of $\mathrm{ECa}_{\mathrm{e}}$ during the wetting transition (September, October, and November 2012) is presumed to reflect the contribution of water with different $\mathrm{EC}_{\mathrm{w}}$ due to subsurface flow through the soil, where the solid matrix can be enriched with ions due to the process of evaporation and consequent precipitation of ions. Furthermore, the poor correlation between $\mathrm{ECa}_{\mathrm{e}}$ and $\theta_{\mathrm{d}}$ for the measurement dates in May 2013 and during the wetting transition was determined by the fact that the soil in the valley bottom did not show significantly higher $\theta_{\mathrm{d}}$ compared to the soils on the slopes, as it occurred, instead, for the measurement dates in April, July, and August 2013 (Fig. 4). This can be explained with the lower $\theta_{\mathrm{d}}$ in the topsoil and intermediate soil horizon $\left(\theta_{\mathrm{d}, 05}\right.$ and $\theta_{\mathrm{d}, 25}$, respectively) for the valley bottom (Martini et al., 2015), and with the occurrence of the flood event in May 2013, when the soil reached saturation in large portions of the entire Schäfertal catchment, locally with overland flow. Under such conditions, $\mathrm{EC}_{\mathrm{w}}$ could be altered by the flushing of soil organic matter, nutrients and ions released from the solid matrix of the soil from the catchment. Another reason for the different $\mathrm{ECa}_{\mathrm{e}}$ patterns observed (measurement dates in September, October, and November 2012 and May 2013, on one hand, and April, July, and August 2013, on the other hand, Table 2) lies in the varying relative position of STU 1 and STU 4 along the $x$ axes (i.e., in terms of ECa). Based on the interpretation discussed above, such differences can be attributed to the occurrence of different water infiltration and transport processes which may take place at different positions according to local soil properties and nonlocal factors such as topography, and therefore influence the within-field variability $\mathrm{EC}_{\mathrm{w}}$. It is important to remark that measurements of $\mathrm{EC}_{\mathrm{w}}$ are not 
available for the Schäfertal hillslope site with adequate spatial coverage. However, for the different states of soil moisture, distinct hydrological processes were described as taking place at different locations within the hillslope area and at different soil horizons. This knowledge, based on highresolution monitoring of soil water content combined with information on spatial heterogeneity of soil characteristics, enabled inference of spatial and temporal changes of variables (including $\mathrm{EC}_{\mathrm{w}}$ ) relevant for $\mathrm{ECa}$ data interpretation.

The spatial pattern of $\mathrm{ECa}_{\mathrm{e}}$ (Table 2) appears to mirror primarily the spatial heterogeneity of soil textural properties, i.e., higher ECa for the valley bottom (STU 3) than for the slopes (STUs 1, 2, and 4). The occurrence of different hydrological processes (e.g., water infiltration and transport through the vadose zone as well as dynamics of the groundwater level) which take place at different positions along the slope can modify $\mathrm{EC}_{\mathrm{w}}$ differently and, in turn, induce small changes in the ECa pattern. In summary, our observations suggest that static soil properties (such as texture, porosity, and organic matter content) and superimposed temporal variations of $\mathrm{EC}_{\mathrm{W}}$ control the spatial pattern of $\mathrm{ECa}$ measured with EMI at our site. Soil moisture itself has only a minor effect on $\mathrm{ECa}$, although it is clear that it acts as the carrying agent for transporting the ions leading to $\mathrm{EC}_{\mathrm{w}}$. Given the proven site-specific nature of EMI applied to soil studies and the relatively strong correlations that have been recorded between soil water content and ECa at some other locations, it seems important to acknowledge that this statement is not necessarily valid at all sites. However, the strength of the relationship between ECa and soil moisture can only be evaluated if data measured during different hydrological states are available. This is also obvious from our data since it must be considered that if EMI surveys would have been conducted only on measurement dates in April, July, and August 2013, ECa would have been interpreted as a reasonable proxy for $\theta$ (Fig. 4), which clearly shows the importance of time-series data for proper interpretation of EMI. It is evident from Fig. 4 that the range of ECa remained rather constant for the seven measurement dates, although $\theta$ varied significantly. The variability of ECa within a single STU was rather small, especially for the soils on the slopes, and the $\mathrm{ECa}_{\mathrm{e}}-\theta_{\mathrm{d}}$ relationship in Fig. 4 is controlled by the relative position of the STU clusters. As a consequence, the correlations between $\mathrm{ECa}_{\mathrm{e}}$ and $\theta_{\mathrm{d}}$ may become more evident when applied to a site with more contrasting soil properties: for instance, if only STU 1 and STU 3 would be considered for the Schäfertal hillslope site, rather high $R^{2}$ values would be found, simply because the two soils show constantly lower $\mathrm{ECa}_{\mathrm{e}}$ and lower $\theta_{\mathrm{d}}$, and consistently higher $\mathrm{ECa}_{\mathrm{e}}$ and higher $\theta_{\mathrm{d}}$, respectively. In contrast, if soils with similar texture would be considered (e.g., only the soils on the slopes, excluding the STU 3), no correlation would be found between $\mathrm{ECa}_{\mathrm{e}}$ and $\theta_{\mathrm{d}}$ throughout the monitoring period, because there are no clear differences in $\mathrm{ECa}_{\mathrm{e}}$ among STUs 1, 2, and 4 (Fig. 4), and because changes of $\theta_{\mathrm{d}}$ do not affect $\mathrm{ECa}_{\mathrm{e}}$, unless they are responsible for sig- nificant variations of $\mathrm{EC}_{\mathrm{w}}$. But the latter effect would in turn lead to comparable changes on both slopes.

\section{Using EMI for mapping soil moisture and implications for soil mapping}

It is widely acknowledged that EMI surveys offer the potential to map the soil spatial variability over large areas within relatively short time, non-invasively and with high spatial resolution (e.g., Doolittle and Brevik, 2014). This makes EMI methods an important aid for optimizing the number of soil samples required to generate a soil map, and for the numerous applications which require detailed soil maps. The results of this study show the importance of repeated surveys in order to capture the dynamics of the spatial pattern of ECa. This, combined with a sound interpretation of the factors controlling such dynamics, allows for obtainment of the most reliable information from the ECa maps. With respect to that, EMI-based ECa maps can certainly be important supports for hydrological studies, as repeated EMI surveys at one site provide the opportunity to identify stable patterns of soil ECa controlled by the spatial heterogeneity of soil properties, which in turn have important effects on the soil water dynamics.

Similar to our findings, Zhu et al. (2010) observed that "wetter sites were generally distributed in the areas with lower elevations, gentler slopes, and depressional landscape positions. These areas also corresponded to a shallower water table and deeper depth to bedrock. These observations suggest that soil ECa is more soil moisture dependent in wetter landscape positions than in drier positions". For the Schäfertal site, the increase in soil EC can be related to two different reasons: (i) to the wetting of the shallower sections of the soil profile with higher clay content and higher organic matter content (peat soils of the valley bottom), which leads to a release of adsorbed ions from the mineral and organic surfaces and thus releases ions to the soil solution, or (ii) to the flushing of the valley bottom by groundwater with higher electrical conductivity, which would also lead to an increase in soil ECa .

The observed temporal variations of the $\mathrm{ECa}_{\mathrm{e}}-\theta_{\mathrm{d}}$ relationship clearly showed that soil moisture at the Schäfertal site is not the major control on the measured ECa values, and temporal changes of the ECa pattern are to a large extent unrelated to changes of soil moisture. For EMI measurements conducted at different dates and for different moisture conditions, Farahani et al. (2005) found that higher $\theta$ does not necessarily correspond to higher ECa values, which is in good agreement with our observations. Furthermore, Zhu et al. (2010) described that the wetness condition was not the only factor influencing the spatial variability of ECa at their site, and that terrain and soil properties masked the effects of soil moisture on ECa during dry periods, whereas soil ECa was strongly influenced by $\theta$ during wetter periods and at 
wetter locations. Shanahan et al. (2015) found different $\mathrm{ECa}-$ $\theta$ relationships between a sandy clay loam and a loamy sand, but for both, soil EC decreased with depth, although gravimetric soil water content at depth was higher than or similar to that at the surface.

Referring to the soil equivalent resistance model (Rhoades et al., 1989) on the physical principle behind the ECa measurements, Corwin et al. (2008) discussed the complexity of ECa measurements as being influenced by any soil property or state that influences electrical conductance pathways in soils, and explained that most of the soil properties that influence bulk soil electrical conductivity exhibit co-dependency and thus provide overlapping information on ECa. Furthermore, our data clearly show that the relationship between ECa and a given soil property or state is time-ofmeasurement-dependent, which results from the dynamic nature of, e.g., groundwater levels, soil water content, and concentration of pore water solution which influence the electrical conductance pathway. This is also confirmed by field data presented in Farahani et al. (2005), and the authors argued that the relationship that they observed between ECa and $\theta$ can be partially explained by the dependency of $\theta$ on stable soil properties, such as clay content. Furthermore, they showed that such behavior may produce the effect of magnifying the relationship between ECa and a given soil property at certain times. In the same direction, our results clearly show the difficulties of simply relating ECa to $\theta$. The few differences of soil texture and the rather low clay content at the Schäfertal hillslope site are responsible for the small range of measured ECa.

Corwin et al. (2008) observed that, at sites where dynamic variables (e.g., salinity) dominate the ECa measurement, temporal changes in spatial patterns exhibit more fluidity than systems that are dominated by static properties (e.g., soil texture). Other studies (Zhu et al., 2010; Robinson et al., 2012; Calamita et al., 2015) observed larger spatial variability of soil ECa during the wetter periods and stronger correlation of ECa with clay and topography patterns, as well as poor spatial organization under dry conditions, supporting the concept of preferred soil moisture states as described in Grayson et al. (1997).

In addition to that, important aspects to be considered in the interpretation of EMI-based ECa data are the volume of investigation of the EMI instrument and its spatial sensitivity. Callegary et al. (2007) found that the instrument vertical sensitivity varied significantly both for homogeneous and heterogeneous soils although the general shape of all cumulative sensitivity distributions was similar to those predicted by McNeill (1980), which holds true only for non-conductive soils, and decreases with increasing ECa. In a more recent study (Callegary et al., 2012), the same authors simulated the distribution of the EM field in a 3D space, and found that the sensitivity pattern has a highly complex shape, including areas of negative contribution (i.e., conductive anomalies may contribute negatively to the instrument ECa reading). This implies that caution is required when the ECa data are to be used quantitatively, as the volume of soil sensed by the EMI device may change spatially and temporally. Such an effect may not be a severe limitation for the Schäfertal site, where bulk soil electrical conductivity is low, but may be significant for more conductive soils or with more contrasting soil textures.

Given the complexity of the EM field propagation through natural soils (hence, with a certain degree of heterogeneity) any quantitative interpretation of ECa data (e.g., for estimating $\theta$ or solute concentration) is difficult to prove with field data from EMI measurements only. In fact, for every point in space where EMI measurements are conducted, measured $\mathrm{ECa}$ resembles the bulk conductivities of all sources contributing to $\mathrm{ECa}$. These are $\mathrm{EC}_{\mathrm{s}}$, and $\mathrm{EC}_{\mathrm{w}}$ for the actual volume of investigation of the EMI sensor, which changes according to variations in the electrical conductivity profile. The water itself does not contribute to the soil EC. However, it is the carrying agent for ions released into the pore water, and it is responsible for the thickness of water films around the minerals which themselves control the mobility of ions therein, and consequently affect soil EC (Friedman, 2005).

Interdisciplinary combination of expertise and the use of well-constrained numerical models can certainly improve our ability to extract reliable information from EMI-based ECa datasets. This is not trivial, and involves the fields of pedology, hydrology, soil physics, soil chemistry, and geophysics, as it must account for the propagation of the EM field through the heterogeneous soil material, where complex interactions between stable soil properties and transient state variables take place and are spatially and temporally dynamic. Furthermore, such models need to be trained with time series of highly resolved spatial data.

Benefits to the use of EMI-based ECa data may arise from the use of multiconfiguration EMI systems and calibration procedures, as they allow for collection of ECa data from multiple depths at the same time. Following the original work of Lavoué et al. (2010) and its further improvement by Mester et al. (2011), recent studies (e.g., Von Hebel et al., 2014; Shanahan et al., 2015) promoted the calibration of $\mathrm{ECa}$, collected using multiconfiguration EMI, based on inverted electrical resistivity tomography (ERT) data. This is probably the most advanced approach available nowadays for calibrating EMI measurements collected at different points in space and in time. Nevertheless, the reliability of this calibration procedure still appears limited due to a number of fundamental issues which are not solved yet. Among others, a major source of uncertainty is due to the fact that the solution of ERT inversion is non-unique (e.g., Keller and Frischknecht, 1966; Koefoed, 1979; Sharma and Kaikkonen, 1999; Dafflon et al., 2013). Consequently, the risk exists to adjust the EMIbased ECa data to soil EC profiles which do not match reality, and little control is offered about the uncertainties. Furthermore, existing calibration approaches rely on the standard vertical sensitivity function of EMI (McNeill, 1980), which 
is only valid for homogeneous and nonconductive soils and is not easily applicable to natural soils, as clearly illustrated by the works of Callegary et al. $(2007,2012)$. However, even if all issues would be solved, multi-depth calibrated ECa data from ERT inversion can provide depth-resolved information on soil electrical conductivity only. The separation of soil moisture from all the other properties and states that influence the EMI measurement will still remain a challenge. In a recent study, Michot et al. (2016) illustrated some of the issues related to the use of ERT for soil moisture estimation. Soil spatial heterogeneity was found to be responsible for the nonstationary nature of the relationship between electrical resistivity (ER) and $\theta$ in a heterogeneous soil system. Moreover, the authors argued that changes of ER were probably related to changes of $\mathrm{EC}_{\mathrm{W}}$ (controlled by soil-plant interactions and infiltration processes), as $\theta$ remained unchanged.

As soil and consequently also water and solute dynamics are spatially heterogeneous, ideally it would be required to calibrate every single measurement point within a study site for each measurement date. A proper calibration of ECa for soil moisture monitoring would only be possible if the temporal variations of all other state variables that induce codependencies on $\mathrm{ECa}$ (such as temperature and $\mathrm{EC}_{\mathrm{W}}$ ) could be determined and if the influence of the water content on ECa would be strong enough to make it measurable with EMI. This would be an enormous effort and to our knowledge there are no published works which attempted such an ambitious site characterization. We consider the dataset presented in this study as one of the most complete with respect to EMI- $\theta$ studies; nevertheless, this is still not adequate to provide data suitable for proper calibration of ECa.

Similar difficulties exist for multi-frequency EMI sensors. Tromp-van Meerveld and McDonnell (2009) could not resolve the $\theta$ depth profile using an EMI sensor comprising six frequencies, which provided similar responses for six different frequencies, although the distribution of $\theta$ with depth was non-uniform due to rain events. The study of Calamita et al. (2015) showed similar limitations, and the authors highlighted that a number of factors can make the interpretation of ECa data with respect to $\theta$ challenging, and that the use of the EMI method for hydrological applications can be better understood when considering the effects of $\mathrm{EC}_{\mathrm{w}}$ and clay minerals.

Shanahan et al. (2015) remarked that in ECa- $\theta$ studies it is commonly assumed that a change in soil EC is simply due to a change in the volume of the fluid. Nevertheless their study showed that, under certain circumstances, changes in EMIbased ECa may be confounded by increased $\mathrm{EC}_{\mathrm{W}}$ and less closely associated with changes in $\theta$. Cassiani et al. (2015) remarked on the need for more consideration for $\mathrm{EC}_{\mathrm{w}}$, which may play an important role. Our study confirms this, at least for the case of low-conductive soils, and shows that the large changes of $\theta$ at the Schäfertal site have negligible effects on the measured ECa. Different results may be found for different soil types. In fact, a larger ECa response to changes in $\theta$ was observed for clay-rich soils (e.g., Martinez et al., 2010; Robinson et al., 2012; Shanahan et al., 2015). Good relationships between ECa and soil moisture may be achieved locally and for certain soil conditions, triggered by co-dependencies between most of the properties and states that influence ECa.

Our results apply to the Schäfertal site and to landscapes with similar soil characteristics (low conductive silty loam soils evolved on loess deposits are widespread over large areas of central and northern Europe) and call for proper interpretation of $\mathrm{ECa}$, which respond to complex physicochemical properties of soil. To this end, an interdisciplinary approach, combining pedological and hydrological expertise with a solid understanding of the (geo)physical principles underlying the EMI method, may certainly improve the results of future studies.

\section{Summary and conclusions}

Repeated EMI surveys were conducted on a hillslope site within the Schäfertal catchment, of which soil properties and soil moisture dynamics were known. Soil ECa was mapped on seven dates with different soil moisture states, comprising dry, wet, and transition from dry to wet. This allowed for investigation of the effects of $\theta$ on the measured ECa under field conditions and provided the opportunity to discuss the physical principles behind EMI measurements of ECa.

Although the range of $\theta$ variations was very large throughout the monitoring period, ECa showed a very small range of variation. Temporal changes in spatial patterns of ECa were found to differ from temporal changes in spatial patterns of $\theta$. The observations discussed in the present work support the conclusion that soil moisture is not the major control on the bulk soil electrical conductivity measured with EMI, which is, indeed, controlled by a number of soil properties and states with a variable and time-varying relative contribution. It is worth remarking that time-series data have the potential to reveal the limits of applicability of the EMI method with respect to the specific site conditions and to avoid overinterpretation of geophysical proxies.

Comparing repeated EMI measurements with highresolution monitoring of soil water dynamics in the vadose zone allowed us to identify two distinct spatial patterns of ECa: the one representing the actual heterogeneity of soil properties, i.e., under dry conditions (July and August 2013) or when $\mathrm{EC}_{\mathrm{w}}$ was presumably low (April 2013), and the other, when different processes, such as water infiltration and transport through the soil and dynamics of the groundwater from the catchment, modify $\mathrm{EC}_{\mathrm{w}}$ and in turn change the signal from the stable pattern of soil properties (e.g., in September, October, and November 2012 and May 2013). Furthermore, our observations suggest that for soils with low clay content, $\theta$ itself has little influence on the measured ECa unless the electrical conductivity of the soil solution changes significantly. 
The combination of repeated EMI measurements and distributed soil moisture monitoring at one site enabled us to provide a process-based interpretation of the relationship between ECa measured with EMI and soil moisture, beyond the limits which we might be subject to if only one method were available.

Experimental evidences and data interpretation provided with this research promote a careful use of the EMI method for any environmental application. Time-lapse measurements of ECa conducted with multiconfiguration EMI can enable the capture of the spatial variation (including depth information) of soil properties as well as the temporal dynamics of the variables involved. Datasets with these characteristics, inverted based on well-calibrated physically based numerical models that are able to represent the spatial and temporal patterns of, ideally, all properties and states which influence soil bulk electrical conductivity, can certainly improve our ability to extract reliable information on environmental variables of interest that can be used quantitatively. However, this may not be feasible for all sites, as it requires large technical efforts and combined expertise in different fields of research. In such cases, repeated EMI mapping can still provide the opportunity to noninvasively map the soil heterogeneity of the site, which makes EMI an important aid for any environmental research.

\section{Data availability}

The data will be made available to all interested researchers upon request to the author (edoardo.martini@ufz.de).

Competing interests. The authors declare that they have no conflict of interest.

Acknowledgements. This research has received funding from ExpeER, a project funded by the European Commission's Seventh Framework Programme and from the Helmholtz Alliance EDA Remote Sensing and Earth System Dynamics, through the Initiative and Networking Fund of the Helmholtz Association, Germany. In addition, it was supported by TERENO (TERrestrial ENvironmental Observatories) and by WESS - Water and Earth System Sciences Competence Cluster (Tübingen, Germany). Edoardo Martini acknowledges the support of HIGRADE, the Helmholtz Interdisciplinary Graduate School for Environmental Research. Hendrick Paasche (UFZ - Hemholtz Centre for Environmental Research, Leipzig, Germany) is gratefully acknowledged for discussion on the paper. We gratefully acknowledge S. Gerlach (Agrargenossenschaft Straßberg-Siptenfelde), who provided access to the site and logistical support, and the colleagues who helped to conduct the EMI surveys. Constructive comments from five anonymous referees and an additional short comment contributed to improving the paper. Data will be made available to all interested researchers upon request.
The article processing charges for this open-access publication were covered by a Research Centre of the Helmholtz Association.

Edited by: N. Romano

Reviewed by: five anonymous referees

\section{References}

Abdu, H., Robinson, D. A., Seyfried, M., and Jones, S. B.: Geophysical imaging of watershed subsurface patterns and prediction of soil texture and water holding capacity, Water Resour. Res., 44, W00D18, doi:10.1029/2008WR007043, 2008.

Abraham, J. D., Deszcz-Pan, M., Fitterman, D. V., and Burton, B. L.: Use of a handheld broadband EM induction system for deriving resistivity depth image, in: Symposium on the Application of Geophysics to Engineering and Environmental Problems, 2-6 April 2006, Seattle, Washington, 1782-1799, doi:10.4133/1.2923642, 2006.

Al-Gaadi, K.: Employing electromagnetic induction techniques for the assessment of soil compaction, Am. J. Agr. Biol. Sci., 4, 425434, 2012.

Altdorff, D., Bechtold, M., van der Kruk, J., Vereecken, H., and Huisman, J. A.: Mapping peat layer properties with multi-coil offset electromagnetic induction and laser scanning elevation data, Geoderma, 261, 178-189, doi:10.1016/j.geoderma.2015.07.015, 2016.

Anderson-Cook, C. M., Alley, M. M., Roygard, J. K. F., Khosla, R., Noble, R. B., and Doolittle, J. A.: Differentiating soil types using electromagnetic conductivity and crop yield maps, Soil Sci. Soc. Am. J., 66, 1562-1570, 2002.

Binley, A., Hubbard, S. S., Huisman, J. A., Revil, A., Robinson, D. A., Singha, K., and Slater, L. D.: The emergence of hydrogeophysics for improved understanding of subsurface processes over multiple scales, Water Resour. Res., 51, 3837-3866, doi:10.1002/2015WR017016, 2015.

Bogena, H., Herbst M., Huisman, J. A., Rosenbaum, U., Weuthen, A., and Vereecken, H.: Potential of wireless sensor networks for measuring soil water content variability, Vadose Zone J., 9, 1002-1013, doi:10.2136/vzj2009.0173, 2010.

Borchardt, D.: Geoökologische Erkundung und hydrologische Analyse von Kleineinzugsgebieten des unteren Mittelgebirgsbereichs, dargestellt am Beispiel der oberen Selke, Harz, Petermanns Geogr. Mitteil., 82, 251-262, 1982.

Brevik, E. C. and Fenton, T. E.: Effect of changes in bulk density on soil electrical conductivity as measured with the Geonics EM-38, Soil Surv. Horizons, 45, 96-102, 2004.

Calamita, G., Perrone, A., Brocca, L., Onoratic, B., and Manfreda, S.: Field test of a multi-frequency electromagnetic induction sensor for soil moisture monitoring in southern Italy test sites, J. Hydrol., 529, 316-329, doi:10.1016/j.jhydrol.2015.07.023, 2015.

Callegary, J. B., Ferré, T. P. A., and Groom, R. W.: Vertical spatial sensitivity and exploration depth of low-induction-number electromagnetic induction instruments, Vadose Zone J., 6, 158-167, doi:10.2136/vzj2006.0120, 2007.

Callegary, J. B., Ferré, T. P. A., and Groom, R. W.: Threedimensional sensitivity distribution and sample volume of low- 
induction-number electromagnetic induction instruments, Soil Sci. Soc. Am. J., 76, 85-91, doi:10.2136/sssaj2011.0003, 2012.

Cassiani, G., Boaga, J., Rossi, M., Fadda, G., Putti, M., Majone, B., and Bellin, A.: Soil-plant interaction monitoring: small scale example of an apple orchard in Trentino, North Eastern Italy, Sci. Total Environ., 543, 851-861, doi:10.1016/j.scitotenv.2015.03.113, 2015.

Corwin, D. L. and Lesch, S. M.: Apparent soil electrical conductivity measurements in agriculture, Comput. Electron. Agric., 46, 11-43, 2005.

CWACEN 16373 - Workshop Agreement: Best practice approach for electromagnetic induction (EMI) measurements of the near surface, CEN, Brussels, Belgium, p. 56, 2011.

Corwin, D. L., Lesch, S. M., and Farahani, H.: Theoretical insight on the measurement of soil electrical conductivity, in: chap. 4, Handbook of Agricultural Geophysics, edited by: Allred, B. J., Daniels, J. J., and Ehsani, M. R., CRC Press, Boca Raton, FL, 59-83, 2008.

Dafflon, B., Hubbard, S. S., Ulrich, C., and Peterson, J. E.: Electrical conductivity imaging of active layer and permafrost in an Arctic ecosystem, through advanced inversion of electromagnetic induction data, Vadose Zone J., 12, doi:10.2136/vzj2012.0161, 2013.

Delefortrie, S., De Smedt, P., Saey, T., Van De Vijver, E., and Van Meirvenne, M.: An efficient calibration procedure for correction of drift in EMI survey data, J. Appl. Geophys., 110, 115125, doi:10.1016/j.jappgeo.2014.09.004, 2014.

Dingman, S. L.: Physical Hydrology, 2nd Edn., Waveland Press, Long Grove, Illinois, 2002.

Doolittle, J. A., Sudduth, K. A., Kitchen, N. R., and Indorante, S. J.: Estimating depth to claypans using electromagnetic inductive methods, J. Soil Water Conserv., 49, 552-555, 1994.

Doolittle, J. A., Petersen, M., and Wheeler, T.: Comparison of two electromagnetic induction tools in salinity appraisals, J. Soil Water Conserv., 56, 257-262, 2001.

Doolittle, J. A., Windhorn, R. D., Withers, D. L., Zwicker, S. E., Heisner, F. E., and McLeese, B. L.: Soil scientists revisit a highintensity soil survey in Northwest Illinois with electromagnetic induction and tradition methods, Soil Surv. Horiz., 49, 102-108, 2008.

Doolittle, J. A. and Brevik, E. C.: The use of electromagnetic induction techniques in soils studies, Geoderma, 223-225, 33-45, doi:10.1016/j.geoderma.2014.01.027, 2014.

El-Qady, G., Metwaly, M., and Khozaym, A.: Tracing buried pipelines using multi frequency electromagnetic, NRIAG J. Astron. Geophys., 3, 101-107, doi:10.1016/j.nrjag.2014.06.002, 2014.

Farahani, H. J., Buchleiter, G. W., and Brodahl, M. K.: Characterization of apparent soil electrical conductivity variability in irrigated sandy and non-saline fields in Colorado, Am. Soc. Agric. Eng., 48, 155-168, 2005.

Friedman, S. P.: Soil properties influencing apparent electrical conductivity: a review, Comput. Electron. Agric., 46, 45-70, 2005.

Frogbrook, Z. L. and Oliver, M. A.: Identifying management zones in agricultural fields using spatially constrained classification of soil and ancillary data, Soil Use Manage., 23, 40-51, 2007.

Grayson, R. B., Western, A. W., Chiew, F. H. S., and Blöschl, G.: Preferred states in spatial soil moisture patterns: local and non-local controls, Water Resour. Res., 33, 2897-2908, doi:10.1029/97WR02174, 1997.

Hauck, C. and Kneisel, C.: Applied geophysics in periglacial environments, Cambridge Univ. Press, Cambridge, UK, 2008.

Hedley, C. B., Yule, I. J., Eastwood, C. R., Sheperd, T. G., and Arnold, G.: Rapid identification of soil textural and management zones using electromagnetic induction sensing in soils, Aust. J. Soil Res., 42, 389-400, 2004.

Heil, K. and Schmidhalter, U.: Characterisation of soil texture variability using the apparent soil electrical conductivity at a highly variable site, Comput. Geosci., 39, 98-110, 2012.

Heilig, J., Kempenich, J., Doolittle, J., Brevik, E. C., and Ulmer, M.: Evaluation of electromagnetic induction to characterize and map sodium-affected soils in the northern Great Plains, Soil Surv. Horiz., 52, 77-88, 2011.

Huang, J., Monteiro Santos, F. A., and Triantafilis, J.: Mapping soil water dynamics by spatio-temporal inversion of electromagnetic induction data, Water Resour. Res., 52, 9131-9145, doi:10.1002/2016WR019330, 2016.

Huang, J., McBratney, A. B., Minasny, B., and Triantafilis, J.: Monitoring soil water dynamics using electromagnetic conductivity imaging and the ensemble Kalman Filter, Geoderma, 285, 7693, doi:10.1016/j.geoderma.2016.09.027, 2017.

Hübner, C., Cardell-Oliver, R., Becker, R., Spohrer, K., Jotter, K., and Wagenknecht, T.: Wireless soil moisture sensor networks for environmental monitoring and vineyard irrigation. In: 8th International Conference on Electromagnetic Wave Interaction with Water and Moist Substances (ISEMA 2009), Helsinki, Finland, 408-415, 2009.

Hudson, B. D.: Soil organic matter and available water capacity, J. Soil Water Conserv., 49, 189-194, 1994.

Islam, M. M., Meerschman, E., Saey, T., De Smedt, P., Van De Vijver, E., Delefortrie, S., and Van Meirvenne, M.: Characterizing compaction variability with an electromagnetic induction sensor in a puddled paddy rice field, Soil Sci. Soc. Am. J., 78, 579-588, 2014.

James, I. T.,Waine, T. W., Bradley, R. I., Taylor, J. C., and Godwin, R. J.: Determination of soil type boundaries using electromagnetic induction scanning techniques, Biosyst. Eng., 86, 421-430, 2003.

Johnson, C. K., Doran, J. W., Duke, H. R., Wienhold, B. J., Eskridge, K. M., and Shanahan, J. F.: Field-scale conductivity mapping for delineating soil condition, Soil Sci. Soc. Am. J., 65, 1829-1837, 2001.

Kaatze, U.: Reference liquids for the calibration of dielectric sensors and measurement instruments, Meas. Sci. Technol., 18, 967 976, 2007.

Keller, G. V. and Frischknecht, F. C.: Electrical methods of geophysical prospecting, in: Vol. 10 of International Series of Monographs in Electromagnetic Waves, Pergamon Press, Oxford, New York, p. 519, 1966.

King, J. A., Dampney, P. M. R., Lark, R. M., Wheeler, H. C., Bradley, R. I., and Mayr, T. R.: Mapping potential crop management zones within fields: use of yield-map series and patterns of soil physical properties identified by electromagnetic induction sensing, Precis. Agric., 6, 167-181, 2005.

Koefoed, O.: Geosounding Principles 1, Resistivity Sounding Measurements, Elsevier, Amsterdam, 1979. 
Kögler, S., Schmidt, F., Martini, E., Bumberger, J., Zacharias, S., and Wollschläger, U.: Comparison of two calibration approaches for low-cost soil moisture sensors, in: 7th CMM Conference 2013 Innovative Feuchtemessung in Forschung und Praxis, 24 September 2013, Karlsruhe, Germany, 2013.

Lal, R. and Shukla, M. K.: Principles of Soil Physics, Marcel Dekker, New York, 2004.

Lausch, A., Zacharias, S., Dierke, C., Pause, M., Kühn, I., Doktor, D., Dietrich, P., and Werban, U.: Analysis of vegetation and soil patterns using hyperspectral remote sensing, EMI, and gamma-ray measurements, Vadose Zone J., 12, doi:10.2136/vzj2012.0217, 2013.

Lavoué, F., van der Kruk, J., Rings, J., Andre, F., Moghadas, D., Huisman, J. A., Lambot, S., Weihermuller, L., Vanderborght, J., and Vereecken, H.: Electromagnetic induction calibration using apparent electrical conductivity modelling based on electrical resistivity tomography, Near Surf. Geophys., 8, 553-561, 2010.

Lück, E., Gebbers, R., Ruehlmann, J., and Spangenberg, U.: Electrical conductivity mapping for precision farming, Near Surf. Geophys., 7, 15-25, 2009.

Martinez, G., Vanderlinden, K., Ordóñez, R., and Muriel, J. L.: Can apparent electrical conductivity improve the spatial characterization of soil organic carbon?, Vadose Zone J., 8, 586-593, 2009.

Martinez, G., Vanderlinden, K., Giraldez, J. V., Espejo, A. J., and Muriel, J. L.: Field-scale soil moisture pattern mapping using electromagnetic induction, Vadose Zone J., 9, 871-881, doi:10.2136/vzj2009.0160, 2010.

Martini, E., Comina, C., Priori, S., and Costantini, E. A. C.: A combined geophysical-pedological approach for precision viticulture in the Chianti hills, Bollettino di Geofisica Teorica ed Applicata, 54, 165-181, doi:10.4430/bgta0079, 2013.

Martini, E., Wollschläger, U., Kögler, S., Behrens, T., Dietrich, P., Reinstorf, F., Schmidt, K., Weiler, M., Werban, U., and Zacharias, S.: Spatial and temporal dynamics of hillslope-scale soil moisture patterns: characteristic states and transition mechanisms, Vadose Zone J., 14, doi:10.2136/vzj2014.10.0150, 2015.

McCutcheon, M. C, Farahani, H. J., Stednic, J. D., Buchleiter, G. W., and Green, T. R.: Effect of soil water on apparent soil electrical conductivity and texture relationships in a dryland field, Biosyst. Eng., 94, 19-32, 2006.

McNeill, J. D.: Electromagnetic terrain conductivity measurement at low induction numbers, Tech. Note TN-6, Geonics Ltd., Mississauga, ON, Canada, 1980.

Mester, A., van der Kruk, J., Zimmermann, E., and Vereecken, H.: Quantitative Two-Layer Conductivity Inversion of MultiConfiguration Electromagnetic Induction Measurements, Vadose Zone J., 10, 1319-1330, 2011.

Michot, D., Thomas, Z., and Adam, I.: Nonstationarity of the electrical resistivity and soil moisture relationship in a heterogeneous soil system: a case study, SOIL, 2, 241-255, doi:10.5194/soil-2241-2016, 2016.

Ollesch, G., Sukhanovski, Y., Kistner, I., Rode, M., and Meissner, R.: Characterization and modelling of the spatial heterogeneity of snowmelt erosion, Earth Surf. Proc. Land., 30, 197-211, doi:10.1002/esp.1175, 2005.

Priori, S., Martini, E., Andrenelli, M. C., Magini, S., Agnelli, A. E., Bucelli, P., Biagi, M., Pellegrini, S., and Costantini, E. A. C.: Improving wine quality through harvest zoning and combined use of remote and soil proximal sensing, Soil Sci. Soc. Am. J., 77, 1338-1348, doi:10.2136/sssaj2012.0376, 2013.

Reinstorf, F.: Schäfertal, Harz Mountains, Germany. Poster, in: Status and Perspectives of Hydrology in Small Basins, Results and reccommendations of the International Workshop in Goslar-Hahnenklee, Germany 2009, and Inventory of Small Hydrological Research Basins, 30 March-2 April 2009, Goslar-Hahnenklee, Germany, edited by: Schumann, S., Schmalz, B., Meesenburg, H., and Schröder, U., available at: http://www.ihp-germany.de/_service/03_Publikationen/01_ IHP_Schriftenreihe/heft10_de.pdf?_blob=publicationFile (last access: 10 August 2016), 2010.

Rhoades, J. D., Manteghi, N. A., Shouse, P. J., and Alves, W. J.: Soil electrical conductivity and soil salinity: new formulations and calibrations, Soil Sci. Soc. Am. J., 53, 433-439, 1989.

Robinson, D. A., Lebron, I., Lesch, S. M., and Shouse, P.: Minimizing drift in electrical conductivity measurements in high temperature environments using the EM-38, Soil Sci. Soc. Am. J., 68, 339-345, 2004.

Robinson, D., Abdu, H., Lebron, I., and Jones, S.: Imaging of hill-slope moisture wetting patterns in a semi-arid oak savanna catchment using time-lapse electromagnetic induction, J. Hydrol., 416-417, 39-49, doi:10.1016/j.jhydrol.2011.11.034, 2012.

Roth, K.: Soil Physics, Lecture Notes, Institute of Environmental Physics, Heidelberg University, Heidelberg, available at: http://www.iup.uni-heidelberg.de/institut/forschung/groups/ ts/soil_physics/students/lecture_notes05 (last access: $10 \mathrm{Au}-$ gust 2016), 2012.

Roth, K., Schulin, R., Flühler, H., and Attinger, W.: Calibration of time domain reflectometry for water content measurement using a composite dielectric approach, Water Resour. Res., 26, 22672273, doi:10.1029/WR026i010p02267, 1990.

Rudolph, S., Wongleecharoen, C., Lark, R. M., Marchant, B. P., Garré, S., Herbst, M., Vereecken, H., and Weihermüller, L.: Soil apparent conductivity measurements for planning and analysis of agricultural experiments: A case study from Western-Thailand, Geoderma, 267, 220-229, 2016.

Saey, T., Simpson, D., Vermeersch, H., Cockx, L., and Van Meirvenne, M.: Comparing the EM38-DD and Dualem-21S sensors to depth-to-clay mapping, Soil Sci. Soc. Am. J., 73, 7-12, doi:10.2136/sssaj2008.0079, 2009.

Sauer Jr., M. C., Southwick, P. F., Spiegler, K. S., and Wyllie, M. R. J.: Electrical conductance of porous plugs: Ion exchange resinsolution systems, Ind. Eng. Chem., 47, 2187-2193, 1955.

Schmidt, K., Behrens, T., Daumann, J., Ramirez-Lopez, L., Werban, U., Dietrich, P., and Scholten, T.: A comparison of calibration sampling schemes at the field scale, Geoderma, 232-234, 243256, doi:10.1016/j.geoderma.2014.05.013, 2014.

Schröter, I., Paasche, H., Dietrich, P., and Wollaschläger, U.: Estimation of catchment-scale soil moisture patterns based on terrain data and sparse TDR measurements using a Fuzzy C-Means clustering approach, Vadose Zone J., 14, doi:10.2136/vzj2015.01.0008, 2015.

Scudiero, E., Corwin, D. L., Wienhold, B. J., Bosley, B., Shanahan, J. F., and Johnson, C. K.: Downscaling Landsat 7 canopy reflectance employing a multi soil sensor platform, Precis. Agric., 17, 53-73, doi:10.1007/s11119-015-9406-9, 2015.

Shanahan, P. W., Binley, A., Whalley, W. R., and Watts, C. W.: The use of electromagnetic induction to monitor changes in soil mois- 
ture profiles beneath different wheat genotypes, Soil Sci. Soc. Am. J., 79, 459-466, doi:10.2136/sssaj2014.09.0360, 2015.

Sharma, S. P. and Kaikkonen, P.: Appraisal of equivalence and suppression problems in 1D EM and DC measurements using global optimization and joint inversion, Geophys. Prospect., 47, 219249, doi:10.1046/j.1365-2478.1999.00121.x, 1999.

Simpson, D., Van Meirvenne, M., Saey, T., Vermeersch, H., Bourgeois, J., Lehouck, A., Cockx, L., and Vitharana, U. W. A.: Evaluating the multiple coil configurations of the EM38DD and DUALEM-21S sensors to detect archaeological anomalies, Archaeol. Prospect., 16, 91-102, 2009.

Sudduth, K. A., Drummond, S. T., and Kitchen, N. R.: Accuracy issues in electromagnetic induction sensing of soil electrical conductivity for precision agriculture, Comput. Electron. Agric., 31, 239-264, doi:10.1016/S0168-1699(00)00185-X, 2001.

Sudduth, K. A., Kitchen, N. R., Wiebold, W. J., Batchelor, W. D., Bollero, G. A., and Bullock, D. G.: Relating apparent electrical conductivity to soil properties across the north-central USA, Comput. Electron. Agric., 46, 263-283, doi:10.1016/j.compag.2004.11.010, 2005.

Triantafilis, J., Laslett, G. M., and McBratney, A. B.: Calibrating an electromagnetic induction instrument to measure salinity in soil under irrigated cotton, Soil Sci. Soc.f Am. J., 64, 1009-1017, 2000.

Triantafilis, J., Lesch, S. M., La Lau, K., and Buchanan, S. M.: Field level digital mapping of cation exchange capacity using electromagnetic induction and a hierarchical spatial regression model, Aust. J. Soil Res., 47, 651-663, 2009.

Tromp-van Meerveld, H. J. and McDonnell, J. J.: Assessment of multi-frequency electromagnetic induction for determining soil moisture patterns at the hillslope scale, J. Hydrol., 368, 56-67, 2009.

U.S.D.A.: Diagnosis and improvement of saline and alkaline soils, in: U.S.D.A. Agricultural Handbook 60, edited by: Richards, L. A., US. Govt. Print. Off., Washington, D.C., 1954.

Vachaud, G. A., Passerat de Silans, A., Balabanis, P., and Vauclin, M.: Temporal stability of spatially measured soil water probability density function, Soil Sci. Soc. Am. J., 49, 822-828, doi:10.2136/sssaj1985.03615995004900040006x, 1985.

Von Hebel, C., Rudolph, S., Mester, A., Huisman, J. A., Kumbhar, P., Vereecken, H., and van der Kruk, J.: Three-dimensional imaging of subsurface structural patterns using quantitative largescale multiconfiguration electromagnetic induction data, Water Resour. Res., 50, 2732-2748, 2014.
Weller, U., Zipprich, M., Sommer, M., Zu Castell, W., and Wehrhand, M.: Mapping clay content across boundaries at the landscape scale with electromagnetic induction, Soil Sci. Soc. Am. J., 71, 1740-1747, 2007.

Werban, U., Kuka, K., and Merbach, I.: Correlation of electrical resistivity, electrical conductivity and soil parameters at a long-term fertilization experiment, Near Surf. Geophys., 7, 5-14, doi:10.3997/1873-0604.2008038, 2009.

Western, A. W., Zhou, S. L., Grayson, R. B., McMahon, T. A., Blöschl, G., and Wilson, D. J.: Spatial correlation of soil moisture in small catchments and its relationship to dominant spatial hydrological processes, J. Hydrol., 286, 113-134, 2003.

Wollschläger, U., Attinger, S., Borchardt, D., Brauns, M., Cuntz, M., Dietrich, P., Fleckenstein, J. H., Friese, K., Friesen, J., Hildebrandt, A., Jäckel, G., Kamjunke, N., Knöller, K., Kögler, S., Kolditz, O., Krieg, R., Kumar, R., Lausch, A., Liess, M., Marx, A., Merz, R., Mueller, C., Musolff, A., Norf, H., Rebmann, C., Reinstorf, F., Rode, M., Rinke, K., Samaniego, L., Vieweg, M., Vogel, H.-J., Weitere, M., Werban, U., Zink, M., and Zacharias, S.: The Bode Catchment as part of the TERENO Harz/Central German Lowland Observatory: A platform for integrated, interdisciplinary eco-hydrological research, Environ. Earth Sci., 76, 29, doi:10.1007/s12665-016-6327-5, 2017.

Won, I. J. and Huang, H.: Magnetometers and Electromagnetometers, Leading Edge, 23, 448-451, 2004.

Zacharias, S., Bogena, H., Samaniego, L., Mauder, M., Fuß, R., Pütz, T., Frenzel, M., Schwank, M., Baessler, C., ButterbachBahl, K., Bens, O., Borg, E., Brauer, A., Dietrich, P., Hajnsek, I., Helle, G., Kiese, R., Kunstmann, H., Klotz, S., Munch, J. C., Papen, H., Priesack, E., Schmid, H. P., Steinbrecher, R., Rosenbaum, U., Teutsch, G., and Vereecken, H.: A network of terrestrial environmental observatories in Germany, Vadose Zone J., 10, 955-973, doi:10.2136/vzj2010.0139, 2011.

Zhu, Q., Lin, H., and Doolittle, J.: Repeated electromagnetic induction surveys for determining subsurface hydrologic dynamics in an agricultural landscape, Soil Sci. Soc. Am. J., 74, 1750-1762, doi:10.2136/sssaj2010.0055, 2010. 